\title{
Numerical Study of an Individual Taylor Bubble Rising through Stagnant Liquids under Laminar Flow Regime
}

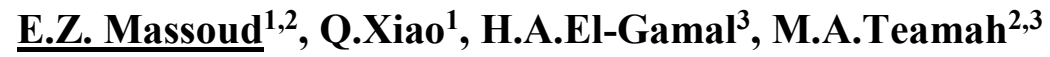 \\ ${ }^{1}$ Department of Naval Architecture, Ocean and Marine Engineering, University of Strathclyde, Glasgow G4 \\ OLZ, Scotland, UK \\ ${ }^{2}$ Mechanical Engineering Department, Arab Academy for Science and Technology and Maritime Transport, \\ Alexandria, Egypt. \\ ${ }^{3}$ Mechanical Engineering Department, Faculty of Engineering, Alexandria University, Alexandria, Egypt.
}

\begin{abstract}
Slug flow is one of the main flow regimes encountered in multiphase flow systems especially in oil and gas production systems. In the present study, the rise of single Taylor bubble through vertical stagnant Newtonian liquid is investigated by performing complete dimensionless treatment followed by an order of magnitude analysis of the terms of equations of motion. Based on this analysis, it is concluded that Froude, Eötvös and Reynolds numbers are the sole physical parameters influencing the dimensionless slug flow equations. Using the guidelines of the order of magnitude analysis, computational fluid dynamics simulation is carried out to investigate the dynamics of Taylor bubbles in vertical pipe using the volume-of-fluid (VOF) method. Good agreement with previous experimental data and models available in the literature is established confirming that the density ratio, viscosity ratio and the initial ratio of bubble size to pipe diameter $\left(L_{T B} / D\right)$ have minimal effect on the main hydrodynamic features of slug flow. Based on the developed results, correlations for the terminal velocity of the Taylor bubble and the dimensionless wall shear stress are proposed showing the significance of these main dimensionless parameters and support other important theoretical and experimental work available in the literature.
\end{abstract}

Keywords: Slug flow; order of magnitude analysis; Taylor bubble velocity; VOF method 


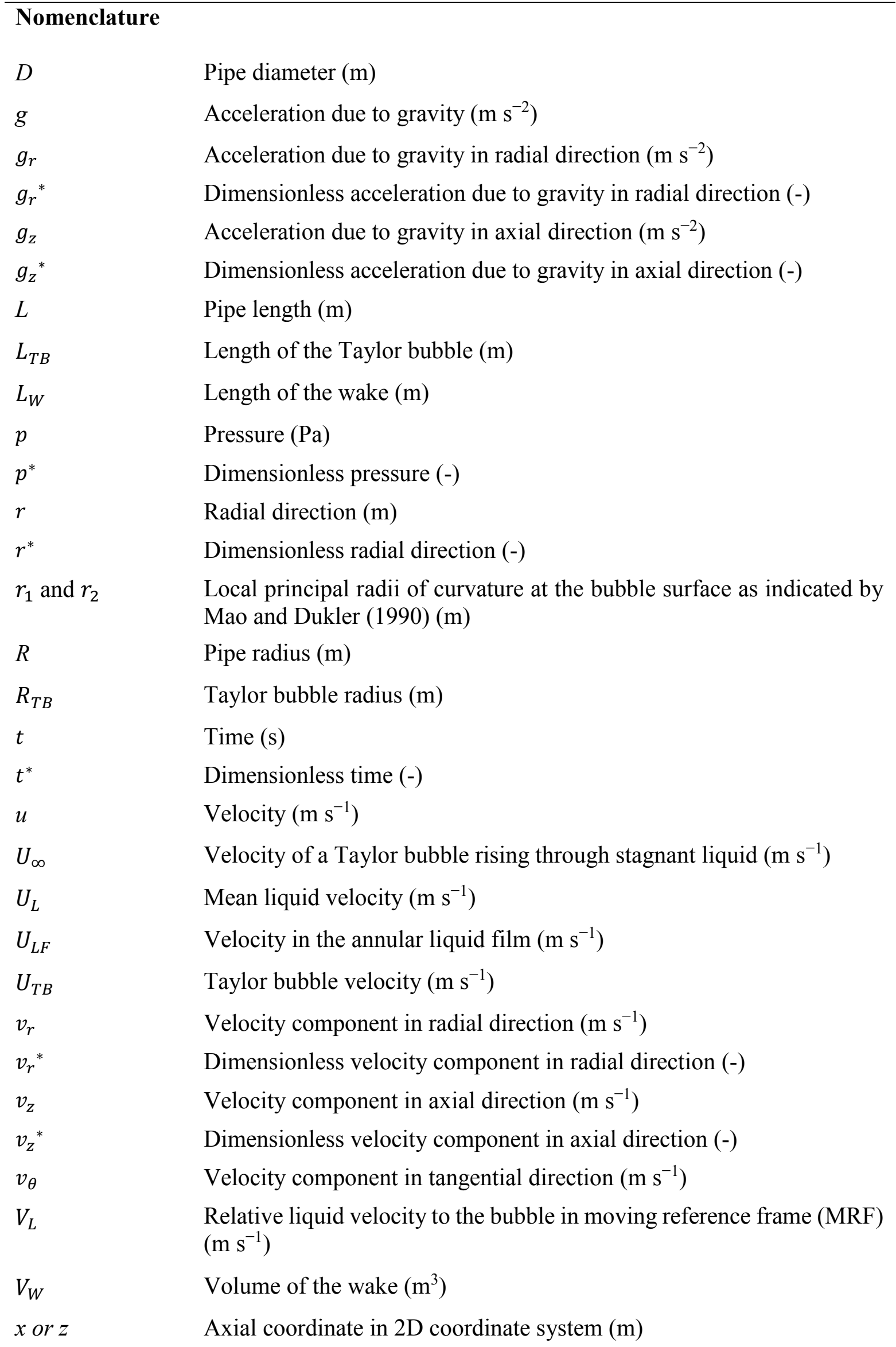


Radial coordinate in 2D coordinate system (m)

Dimensionless axial coordinate (-)

\section{Greek Letters}

$\begin{array}{ll}\mu & \text { Dynamic viscosity }(\mathrm{Pa} \mathrm{s}) \\ \rho & \text { Density }\left(\mathrm{kg} \mathrm{m}^{-3}\right) \\ \sigma & \text { Surface tension }\left(\mathrm{N} \mathrm{m}^{-1}\right) \\ \sigma_{r} & \text { Surface tension in radial direction }\left(\mathrm{N} \mathrm{m}^{-1}\right) \\ \sigma_{r}^{*} & \text { Dimensionless surface tension in radial direction (-) } \\ \sigma_{z} & \text { Surface tension in axial direction }\left(\mathrm{N} \mathrm{m}^{-1}\right) \\ \sigma_{z}^{*} & \text { Dimensionless surface tension in axial direction (-) } \\ \sigma_{\theta} & \text { Surface tension in tangential direction }\left(\mathrm{N} \mathrm{m}^{-1}\right) \\ \sigma_{\theta}^{*} & \text { Dimensionless surface tension in tangential direction (-) } \\ \delta_{L F} & \text { Liquid film thickness }(\mathrm{m}) \\ \tau & \text { Shear stress }(\mathrm{Pa}) \\ \tau_{W} & \text { Wall shear stress }(\mathrm{Pa}) \\ v & \text { Kinematic viscosity }\left(\mathrm{m}^{2} \mathrm{~s}^{-1}\right) \\ \Gamma_{\rho} & \text { Density ratio, } \Gamma_{\rho}=\frac{\rho_{L}}{\rho_{G}} \\ \Gamma_{\mu} & \text { Viscosity ratio, } \Gamma_{\mu}=\frac{\mu_{L}}{\mu_{G}}\end{array}$

\section{Dimensionless groups}

Ar

Eo

$F r_{U T B}$

$M$

$N_{f}$

$R e_{U_{T B}}$ or $R e_{U_{\infty}}$

$R e_{U_{L F}}$

$R e_{V_{L}}$
Archimedes number, $A r=\rho_{L}{ }^{2} g D^{3} / \mu_{L}^{2}$

Eötvös number, $E o=\frac{g \rho_{L} D^{2}}{\sigma}$

Froude number, $F r_{U T B}=\frac{U_{T B}}{\sqrt{g D}}$

Morton number, $M=\frac{\Delta \rho g \mu_{L}^{4}}{\rho_{L}^{2} \sigma^{3}}$

Inverse viscosity number, $N_{f}=\rho_{L}\left(g D^{3}\right)^{0.5} / \mu_{L}$

Reynolds number based on the velocity of the Taylor bubble, $R e_{U_{T B}}=$ $\frac{\rho_{L} U_{T B} D}{\mu_{L}}$

Reynolds number based on the velocity of the annular liquid film, $R e_{U_{L F}}=\rho_{L} U_{L F} \delta_{L F} / \mu_{L}$

Reynolds number based on the mean velocity of the liquid, $R e_{V_{L}}=\rho_{L} V_{L} D / \mu_{L}$ 


\section{List of acronyms}

CFD Computational fluid dynamics

FRF $\quad$ Fixed frame of reference

MRF Moving frame of reference

VOF Volume-of-fluid

\section{Introduction}

Multiphase flows occur in a wide range of applications including natural processes, chemical processes, nuclear systems and petroleum industries. The petroleum industry is considered one of the most important applications of multiphase flow, as it could be encountered in different processes/stages such as: oil processing, oil and gas transport in pipelines, and sloshing in offshore separator devices.

For two-phase gas-liquid flow in pipes, different flow patterns can occur known as "flow pattern/ flow regime". These patterns depend on the flow rates, the geometry of the system, and inclination of the pipe (Morgado et al., 2016). Multiphase flow is classified according to the distribution of different phases building up the flow field, known as "flow regime/pattern". Multiphase flow can be encountered in various flow patterns such as bubbly, slug, plug, annular and dispersed flow. Fluid flow investigation includes an important aspect which is the identification of the encountered flow pattern. For gas-liquid flow in pipes, one of the common and complex patterns encountered is known as "slug flow". Slug flow is an intermitted flow between stratified and annular flow.

Flow intermittence is the main remarkable hydrodynamic characteristic causing the complex structure of slug flow which is composed of Taylor elongated bubble that occupies almost the whole cross-section of the pipe, and annular falling liquid film that might entrain many small bubbles, known as a "liquid slug". Flooding of downstream processing facilities, severe pipe corrosion, structural instability of pipeline, and further induction of the reservoir flow oscillations, and a poor reservoir management are examples of the problems encountered as result of slugging in offshore oil and gas systems.

The prediction of the appropriate flow pattern regimes, the governing correlations, and the hydrodynamic characteristics of slug flow are essential for successful operation, simulation and optimization of any industrial applications encountering slug flow (Santos, 2007). 
According to the following authors, Computational fluid dynamics (CFD) has been proven to be a powerful, practical tool for the analysis and simulation of the hydrodynamic characteristics of slug flow in pipes. The main complex feature of gas-liquid slug flow is the deformable interface (Zheng and Che, 2007). The volume-of-fluid (VOF) method originally developed by Hirt and Nichols (1981) is often used to simulate complex multiphase flows including slug flow, and is powerful in tracking the interface between fluids (Fabre and Liné (1992); Razavi and Namin (2011); Rahimi et al. (2013); Desamala et al. (2013) and Desamala et al. (2014)).

The hydrodynamic characteristics of gas-liquid vertical slug flow include the final shape of the Taylor bubble, Taylor bubble rises velocity, liquid film thickness, liquid film velocity, wall shear stress distribution and wake shape. Despite the conduction of extensive work in the modelling process of gas-liquid slug flow, a need for correlations based on experimental data is still required. These correlations include slug characteristics such as: Taylor bubble velocity, slug frequency, slug length, slug liquid hold up, and slug unit velocity.

In literature, since the 1940s, a significant amount of research has been done to understand the complex principles of slug flow. Starting with Dumitrescu (1943) who investigates the rise of single Taylor bubble in the stagnant liquid by applying potential flow theory and concludes that the Taylor bubble rise velocity could be given by:

$$
U_{T B}=0.351 \sqrt{g D}
$$

Other analytical and/or experimental approaches are made later to modify the above correlation as discussed by Kang et al. (2010). A good review on the most commonly used correlations to estimate the Taylor bubble velocity is given by Morgado et al. (2016).

One of the main complex hydrodynamic features of slug flow is the wake flow pattern. Campos and De Carvalho (1988) performs an important photographic study to investigate the wake structure of Taylor bubbles rising in stagnant liquid using different pipe diameters and liquid viscosities. They conclude that the inverse viscosity number mainly influences the wake structure and they categorise the wake flow pattern into three main groups as follows:

- Type 1: Closed axisymmetric laminar wake for: $N_{f}<500$.

- Type 2: Closed asymmetric transitional wake for: $500<N_{f}<1500$.

- Type 3: Opened turbulent wake with the recirculatory flow: $N_{f}>1500$. 
Araújo et al. (2012) discuss the importance of other experimental studies that investigate the main complex hydrodynamic nature of slug flow. They reach number of remarkable conclusions that helped in further understanding of the problem (Polonsky et al. (1999); Van Hout et al. (2002); Clanet et al. (2004); Liberzon et al. (2006); Sousa et al. (2006), Direito et al. (2017)). Despite the significant effort done in most of the experimental approaches, the need for computation is essential in understanding the complex nature of slug flow problem that eliminates the experimental limitation and the difficulties while providing robust analysis and accurate results. According to the viewed literature, Computational fluid dynamics (CFD) has been proven to be a powerful, practical tool for the analysis and simulation of the hydrodynamic characteristics of slug flow in pipes.

Early attempts to numerical study of slug flow problem are made by Kawaji et al. (1997) that use the volume-of-fluid (VOF) method to numerically investigate the hydrodynamic characteristics of a Taylor bubble rising through the stagnant liquid in a vertical pipe and conclude that the bubble length does not affect the bubble terminal velocity. Based on an iterative scheme that solved the velocity and shape of Taylor bubble in a vertical tube, a different methodology is developed by Clarke and Issa (1997). They introduce a model that assume homogenous flow in the liquid slug region and thus account for the dispersed bubble in that region (Araújo et al., 2012). Against their assumption, the model shows inadequate results that they suggest that future models should use the two-fluid model for proper simulation of the dispersed gas bubbles in the liquid slug region (Ndinisa et al., 2005). Later, Bugg et al. (1998) perform a detailed study on the motion of Taylor bubbles in vertical pipes and prove that the VOF method is capable of determining the main hydrodynamic features of slug flow including the bubble shape, bubble rising velocity, liquid film thickness and average velocity in the liquid film. The results are then compared with experimental data in the literature and show good agreement. Another different approach, based on developing a new algorithm for solving the gas-liquid interface equation, is developed by Issa and Ubbink (1999).

Other significant numerical studies using the VOF method are worth to mention as those done by Ndinisa et al. (2005); Taha and Cui (2006) and Zheng and Che (2007). Lately, Lu and Prosperetti (2008) who numerically study Taylor bubble rising in the stagnant liquid by neglecting the flow in the gas using front tracking method that deals with two-phase liquids and evades the uncertain gas-liquid interface reconstruction in VOF method. They apply a procedure based on B-splines to build smooth functions best-fitting the field variables (velocities in the gas phase) over a strip straddling the gas-liquid interface along with its whole 
perimeter. This method show powerful tracking of the exact position and curvature of the interface that help in calculating the surface tension.

Recently, Kang et al. (2010) use a front tracking methodology to simulate the dynamics of gas slugs rising through stagnant liquids, where the finite difference method is used to discretize the governing equations. The study conclude that the density and viscosity ratios have minimal effect on the dynamics of Taylor bubbles rising in stagnant liquids, while both Eötvös number and Archimedes number have an important impact. They develop correlations for the dimensionless liquid film thickness and the dimensionless wall shear stress as a function of only Archimedes number. They also conclude that wake length and volume depend mainly on Archimedes number. Later, Araújo et al. (2013b) perform a detailed study of the dynamics of Taylor bubble rising in stagnant liquid and include a wide range of Eötvös and Morton number. They show that Kang et al. (2010) correlations are inadequate by proving that both dimensionless liquid film thickness and the dimensionless wall shear stress are function of Eötvös and Morton numbers. They also show that the wake structure is greatly influenced by both Eötvös, and Morton numbers, and not only Archimedes number as concluded by Kang et al. (2010). They are also capable of developing correlations for the wake length and volume that show good agreement with well-known experiment correlations of Campos and De Carvalho (1988).

More recently, Yan and Che (2011) investigate the hydrodynamic characteristics of single Taylor bubble rising in stagnant liquid with further consideration of the small dispersed bubbles in the liquid slug region. Their study account for the effect of small dispersed gas bubbles in liquid slug region on the flow hydrodynamics features and $\mathrm{CO}_{2}$ corrosion rate. It is concluded that the small dispersed gas bubbles result in higher fluctuations in the liquid slug region, which subsequently increase the mass transfer and wall shear stress. Lastly, Araújo et al. (2013a) investigate the rising of two consecutive Taylor bubbles through vertical stagnant Newtonian liquids under laminar regime using the volume-of-fluid (VOF) method. The results account for bubble-bubble interaction and show the dependency of the wake on the separation distance between the bubbles. A good review on slug flow is presented by Morgado et al. (2016) that summarises all of the important correlations used in defining the problem and show the missing data that need to be further investigated.

Despite the significant numerical and theoretical data published on the rise of Taylor bubble through vertical stagnant liquid, to the authors' knowledge there is not yet a study investigating 
the problem using order of magnitude analysis of equations of motions. Hence, the scope of this study can be divided into two main folds:

1. Performing complete dimensionless analysis of the problem using both the BuckinghamPi theorem and a dimensionless treatment followed by an order of magnitude analysis to the governing equations of motion in order to show the sole dimensionless parameters: $R e_{U_{T B}}, F r_{U_{T B}}$, and $E o$ numbers and their relative merits or order of magnitudes. Based on this analysis, the main hydrodynamic features of rising of individual Taylor bubbles through stagnant Newtonian liquids are investigated by applying computational fluid dynamics (CFD) simulation using the volume-of-fluid (VOF) methodology implemented in the commercial software ANSYS Fluent.

2. Developing a correlation between $R e_{U_{T B}}, F r_{U_{T B}}$, and $E o$ numbers based on the developed numerical results and on the guide lines of the order of magnitude analysis to predict Taylor bubble rise velocity $\left(U_{T B}\right)$. This correlation enabled the present study to support other important theoretical and experimental work available in the literature.

\section{Dimensionless equations of motion}

The hydrodynamic characteristics of gas-liquid slug flow are governed by viscous, inertial, gravitational, and interfacial forces. In literature, the problem is mostly analysed into the dimensionless form using Buckingham-Pi theorem.

Morgado et al. (2016) neglect the effect of the expansion of gas during its rise and show that the dimensionless analysis of the problem results in the following form:

$$
\frac{U_{T B}{ }^{2} \rho_{L}}{g D \Delta \rho}=f\left[E o=\frac{g \rho_{L} D^{2}}{\sigma}, M=\frac{\Delta \rho g \mu_{L}^{4}}{\rho_{L}^{2} \sigma^{3}}, \Gamma_{\mu}=\frac{\mu_{L}}{\mu_{G}}, \Gamma_{\rho}=\frac{\rho_{L}}{\rho_{G}}, \frac{L_{T B}}{D}\right]
$$

where the LHS of relation (2) represents the ratio between the inertia and gravitational forces and known by Froude number $\left(\mathrm{Fr}_{U_{T B}}\right)$. Relation (2) can be modified by introducing Reynolds number based on bubble velocity $\left(R e_{U_{T B}}\right)$ which is the ratio between the inertial forces and viscous forces. Eötvös number $(E o)$ is the ratio between gravitational forces, and surface tension forces, and Morton number $(M)$ is known by property group as it only contains the properties of the fluid (Araújo et al., 2012).

It can be shown in this respect that Morton number $(M)$ does not represent any peculiar physical quantity as it can be written as: 


$$
M=\left(\frac{F r_{U_{T B}}}{R e_{U_{T B}}}\right)^{4} E o^{3}=\frac{E o^{3}}{N f^{4}}
$$

where the inverse viscosity number $\left(N_{f}\right)$ is defined as:

$$
N_{f}=\frac{R e_{U_{T B}}}{F r_{U_{T B}}}=\frac{\rho_{L}\left(g D^{3}\right)^{0.5}}{\mu_{L}}
$$

In fact, the inverse viscosity number $\left(N_{f}\right)$ can be interpreted physically as the ratio between gravity force and the viscous force. It is worth noting in this respect that $N_{f}$ and $M$ cannot generally replace $R e_{U_{T B}}$ to judge whether the flow is in its laminar or turbulent regime.

It can be easily shown here that using the Buckingham-Pi theorem can lead to the same form of the dimensionless groups with Morton number replaced by Reynolds number that is given by:

$$
F r_{U_{T B}}=\frac{U_{T B}}{\sqrt{g D}}=f\left[E o=\frac{g \rho_{L} D^{2}}{\sigma}, \operatorname{Re}_{U_{T B}}=\frac{\rho_{L} U_{T B} D}{\mu_{L}}, \Gamma_{\mu}=\frac{\mu_{L}}{\mu_{G}}, \Gamma_{\rho}=\frac{\rho_{L}}{\rho_{G}}, \frac{L_{T B}}{D}\right]
$$

The main governing equations of the problem are the continuity and momentum equations. Dimensionless analysis of these equations followed by the order of magnitude analysis in all directions and on the boundaries is given in details in Appendix 1. The main results are: the radial velocity component $\left(v_{r}{ }^{*}\right)$ should be of order $\left(\frac{D}{L_{T B}}\right)$ in order to keep the continuity equation intact without any approximation; the pressure gradient in the radial direction should be of order $\left(\frac{D}{L_{T B}}\right)^{2}$; for all terms in the momentum equations and on the boundaries to remain of the same order of magnitude, $F r_{U_{T B}}$ should be of order (1), $R e_{U_{T B}}$ and $E o$ both should be of order $\left(\frac{L_{T B}}{D}\right)$. Added to this, referring to Appendix 1, it has been shown that the inverse viscosity number is in fact a modified Reynolds number provided that the characteristic velocity for stagnant fluid given by: $V_{s}=(g D)^{1 / 2}$.

In conclusion, the dimensionless analysis show that any analysis of the problem should include the dimensionless groups: $F r_{U_{T B}}, E o$, and $R e_{U_{T B}}$ or $N_{\mathrm{f}}$. In addition, it is worth to mention that there is no need to using a dimensionless number like Morton number which does not seem to have a direct physical meaning. 
Thus, the problem in the present study is analysed in terms of six main dimensionless groups, namely: Eötvös number $(E o)$, Froude number $\left(F r_{U_{T B}}\right)$, Reynolds number based on bubble velocity $\left(R e_{U_{T B}}\right)$, density ratio $\left(\Gamma_{\rho}\right)$, viscosity ratio $\left(\Gamma_{\mu}\right)$ and the initial ratio of bubble size to pipe diameter $\left(L_{T B} / D\right)$. The present study examines the effects of density ratio $\left(\Gamma_{\rho}\right)$, viscosity ratio $\left(\Gamma_{\mu}\right)$ and the initial ratio of bubble size to pipe diameter $\left(L_{T B} / D\right)$ for the sake of supporting other previous experimental and numerical works in the literature. This is to allow dealing carefully with the main influencing parameters: Eötvös number $(E o)$ and Reynolds number $\left(R e_{U_{T B}}\right)$.

\section{CFD Model development}

The flow domain is constructed and solved using the volume-of-fluid (VOF) methodology implemented in the computational fluid dynamics software package, ANSYS Fluent (Release 15.0). In all simulated cases, a uniform grid of quadrilateral control elements is applied. Different grids depending on domain dimensions have been tested to check solution convergence. The present simulation has been performed for unsteady flow with constant fluid properties. The two phases are assumed as incompressible, viscous, immiscible, and not penetrating each other. The flow regime could be laminar which means the transition or the turbulent is depending on the value of Reynolds number in different flow regions of the slug flow domain.

Figure 1 shows that the flow regions in vertical slug flow that can be divided into three main regions according to the definition of Reynolds number, into flow in main liquid region (liquid slug), $R e_{U_{\infty}}$ or $R e_{U_{T B}}$, flow in liquid film (annular film), $R e_{U_{L F}}$, and flow near bubble wake, $R e_{V_{L}}$. The definition of Reynolds number according to each region is given by:

$$
\begin{gathered}
R e_{U_{T B}}=\rho_{L} U_{T B} D / \mu_{L} \\
R e_{U_{L F}}=\rho_{L} U_{L F} \delta_{L F} / \mu_{L} \\
R e_{V_{L}}=\rho_{L} V_{L} D / \mu_{L}
\end{gathered}
$$

where: $U_{T B}$ is the velocity of Taylor bubble rising through stagnant liquid according to the definition of (Nicklin et al., 1962), $U_{L F}$ is the absolute velocity of the liquid in the stabilized liquid film of thickness $\delta_{L F}$, and $V_{L}$ is the relative liquid velocity to the bubble in moving reference frame (MRF). 
For the case of Taylor bubble rising in stagnant liquid only two parameters, namely: $R e_{U_{\infty}}$, and $R e_{U_{L F}}$, are used to characterize flow type into: laminar, transient, or turbulent flow regime. Various experimental work is done to investigate the characteristic Reynolds number for the onset of transition in the flow regime in each region discussed above. For instance, to ensure laminar flow regime in the main liquid region, $R e_{U_{T B}}$ should be less than 2100 as reported by (Fulford, 1964, Fréchou, 1986, Mayor et al., 2007)

Also, the range of Reynolds numbers for the transitional region in the liquid film region is [250: 400] $<R e_{U_{L F}}<800$ as indicated by Fulford (1964). It should be pointed out that the transition criterion from laminar into turbulent flow is not clear enough and need to be further investigated. For instance, the wake pattern is identified into laminar or turbulent flow according to the value of inverse viscosity number $\left(N_{f}\right)$. Nevertheless, according to the problem definition it should be mainly, in terms of Reynolds number. However according to data in literature, to ensure laminar flow regime in the main liquid region for the present study, $R e_{U_{T B}}$ ought to be less than 200. Regarding the flow in the liquid film, $R e_{U_{L F}}$ never exceeded 30 which ensures that the developed liquid films are entirely under laminar regime.

In the present model, the fluids share a well-defined interface, and hence the volume-of-fluid (VOF) method for two-phase flow has been selected in CFD software ANSYS Fluent (Release 15.0). The VOF model developed by Hirt and Nichols (1981) is a surface-tracking technique applied to a fixed Eulerian mesh. This model is designed for two or more immiscible fluids to track the interface between them. This model solves a single set of momentum equation that is shared by the two fluids, and the volume fraction of each of the fluids in each computational cell is followed throughout the domain. The finite volume method is used to discretize the governing equations. Details of the governing equations and the treatment of the interface can be obtained from Fluent (2015). The continuum surface force (CSF) of Brackbill et al. (1992) is used to account for the surface tension effects.

\subsection{Model geometry and boundary conditions}

The solution domain is a vertical pipe with diameter $(D)$ and length $(L)$ with symmetry along the centreline of the pipe. In order to minimise computational time and effort, all the simulations were performed in axisymmetric flow situation, assuming symmetry about the centerline of the pipe. This assumption is adequate and based on the laminar state of flow. In all simulation cases, the length of domain is eleven times larger than pipe diameter to avoid 
disturbance of the continuous phase (liquid phase) at the entrance and the exit regions, and to ensure that a uniform velocity profile is restored. Figure 1 shows a schematic representation of the computational domain for the present problem. The initial bubble shape is a cylinder connected to a hemisphere with the same radius giving an overall bullet shape of Taylor bubble. The length and radius of the Taylor bubble are given by: $L_{T B}$, and $R_{T B}$ respectively. The initial ratio of Taylor bubble length to pipe diameter $\left(L_{T B} / D\right)_{i}$ is an input parameter prior to simulation and it is fixed to value of 3 in most of the investigated cases except cases 7, 9, and 10 in Table 1. This initial shape is simulated until a steady bubble shape is reached. Different bubble shapes are tested and final steady shape of bubble is found to be similar but this only affects the solution convergence.

The simulation is performed by attaching a reference frame to the rising Taylor bubble. Enabling moving reference frame (MRF) in the simulation, causes the rising Taylor bubble to be stationary and the pipe wall moves downwards with a velocity equal to that of the bubble (Mao and Dukler, 1990). The transformation of the boundary conditions using MRF is given in Figure 1. The initial guess of Taylor bubble velocity $\left(U_{T B}\right)$ is estimated according to the general correlation of Wallis (1969), which is given by:

$$
F r=\frac{U_{T B}}{\sqrt{g D}}=0.345\left(1-e^{\frac{-0.01 N_{f}}{0.345}}\right)\left(1-e^{\frac{3.37-E o}{m}}\right)
$$

where:

$$
m=\left\{\begin{array}{lr}
25, & N_{f}<18 \\
69 N_{f}^{-0.35}, & 18<N_{f}<250 \\
10 & N_{f}>250
\end{array}\right.
$$

Once the Taylor bubble ceases moving up or down in the axial direction, and hence the pseudosteady solution is reached, the velocity is then adjusted and set to be the terminal velocity. The initial guess of the liquid film thickness $\left(\delta_{L F}\right)$ is estimated using Brown (1965) equation, which is given by:

$$
\delta_{L F}=\left[\frac{3 v}{2 g\left(R-\delta_{L F}\right)} U_{T B}\left(R-\delta_{L F}\right)^{2}\right]^{1 / 3}
$$

Referring to Figure 1, using MRF the inlet flow boundary condition is applied with liquid entering at average uniform velocity equal to velocity of Taylor bubble, $U_{i n}=U_{T B}, V_{i n}=0$. At the bottom of the domain, the outflow boundary condition is applied as the liquid phase is 
the only phase available. The symmetry boundary condition is applied at the pipe centreline: $\partial U / \partial y=0, V_{o u t}=0$. At the wall, the no-slip condition is applied with wall moving downwards with the following velocities: $U_{w a l l}=U_{T B}, V_{w a l l}=0$. The gas phase usually has lower density and viscosity than the liquid phase, thus, full slip can be assumed at the gas-liquid interface. The internal circulatory flow within Taylor bubbles has almost negligible effect on the outer surrounding liquid leading to zero interfacial shear stress at the interface. Thus, the pressure variation within Taylor bubble is small and constant pressure is assumed at the interior of the Taylor bubble (Akagawa and Sakaguchi (1966); Mao and Dukler, 1990; Zheng et al., 2007 and Morgado et al. (2016)). Thus, the kinematic condition, $u . n=0$, assuming full slip at the gas-liquid interface is applied. The dynamic boundary condition can be divided into two separate boundary conditions: the tangential stress balance assuming zero interfacial shear stress along the interface: $(\bar{\tau} . \hat{n}) . \hat{s}=0$, and the normal stress balance: $\rho_{i L}+$ $\sigma K=$ constant. According to Mao and Dukler (1990), the curvature of the interface $(K)$ is expressed in terms of radii of the curvature of the bubble surface, as follows:

$$
K=\left[\frac{1}{r_{1}}+\frac{1}{r_{2}}\right]
$$

where: $r_{1}$ and $r_{2}$ are the local principal radii of curvature at the bubble surface as indicated by Mao and Dukler (1990).

\subsection{Solution strategy and convergence criterion}

A time-dependent simulation is carried out in the present case to investigate the unsteady behaviour of two-phase slug flow. The simulation is carried out using the explicit VOF model. The PISO pressure-velocity is selected. The spatial discretization scheme used is as follows: Green-Gauss Node Based for the gradient, PRESTO for pressure, Geo-reconstruct for volume fraction, a Quick scheme for momentum, and first-order implicit for unsteady formulation. The scaled absolute values of the residual of the calculated values of mass, velocity in $\mathrm{x}$, and $\mathrm{y}$ directions are monitored, and convergence criterion of $10^{-4}$ is set for each time step, with a maximum number of iterations of 1000 . The variable time step is applied to the governing equations with global Courant number fixed to 0.25 .

\section{Results and discussions}

In this section, a mesh dependence study is firstly introduced, which is then followed by validation study of single Taylor bubble rising through aqueous glycerol solution and finally 
the main results. The present study aims at investigating the main hydrodynamic features of the rise of single Taylor bubble through stagnant Newtonian fluid including Taylor bubble shape, Taylor bubble rise velocity $\left(U_{T B}\right)$, liquid film thickness $\left(\delta_{L F}\right)$, maximum liquid film velocity $\left(U_{L F}\right)$, wall shear stress $\left(\tau_{W}\right)$, and wake length $\left(L_{w}\right)$, and wake volume $\left(V_{w}\right)$ (as shown in Figure 1) with particular focus on the governing dimensionless numbers: Eötvös number and Reynolds number. The results are then divided into four sections: Taylor bubble shape, Taylor bubble rise velocity, flow in the liquid film region, and flow in the wake region. In addition, correlations for the terminal velocity of the Taylor bubble, and for the dimensionless wall shear stress are proposed showing the significance of these main dimensionless parameters.

Table 1 lists the simulation cases and their corresponding results. The ranges of Eo, $\operatorname{Re}_{U_{T B}}, F_{U_{T B}}, \Gamma_{\rho}, \Gamma_{\mu},\left(L_{T B} / D\right)_{i}$ are 6-700, 2.6-165, 0.031-0.330, 60-200, 66.7-6674, and 2-10, respectively. The input parameters prior simulation are: $E o, \Gamma_{\rho}, \Gamma_{\mu},\left(L_{T B} / D\right)_{i}$, while the predicted values from the simulation are: $\operatorname{Re}_{U_{T B}}, F_{U_{T B}},\left(L_{T B} / D\right)_{p}\left(\delta_{L F} / D\right), U_{L F_{\text {max }}}$, $\left(\frac{\tau_{W}}{\rho_{L} g D}\right)_{\max }, L_{W} / D$, and $V_{W} / D^{3}$. The initial ratio of bubble size to pipe diameter is given by $\left(L_{T B} / D\right)_{i}$ and the average predicted of bubble size to pipe diameter is given by $\left(L_{T B} / D\right)_{p}$.

\subsection{Mesh dependence study}

A uniform grid of quadrilateral control elements is used in the present CFD simulation. A mesh dependence test is done to ensure grid independence results. Three different grid densities are used to simulate a selective experimental case of Campos and De Carvalho (1988) air and aqueous glycerol solution as working fluids in $19 \mathrm{~mm}$ inner diameter vertical pipe. The relevant dimensionless numbers of the selected case are: $E o=64, \operatorname{Re}_{U_{T B}}=60, F r_{U_{T B}}=0.3409$.

Table 2 shows the mesh characteristics, the relevant selected hydrodynamic characteristics to be examined and the corresponding deviations ( $\left.E o=64, R e_{U_{T B}}=60, F r_{U_{T B}}=0.3409\right)$. The reference mesh for the deviation calculation is the denser mesh $(104 \times 1120$ elements). It can be assumed that the results are completely independent particularly when using mesh 2 and mesh 3. Subsequently, based on the results shown in Table 1, the current simulations are conducted using either Mesh 2 or Mesh 3 depending on pipe geometry. 


\subsection{Validation of the computational code}

In this section, a primary validation of the current numerical code based on the experimental work of Nogueira at al. (2006a\&b) on a single Taylor bubble rising through stagnant viscous liquid under laminar flow regime is presented. The experimental condition corresponds to $E o=186, R e_{U_{T B}}=37.083, F r_{U_{T B}}=0.3355$. Figure 2 shows the numerical results for the flow field including the streamlines and velocity vectors for the selected experimental case using moving reference frame (MRF). From this figure, the flow can be divided into three regions: $a, b$ and $c$ namely: Taylor bubble nose region, falling liquid film region and Taylor bubble wake region (liquid slug zone). In the Taylor bubble nose region, the Taylor bubble moves up with velocity $\left(U_{T B}\right)$ due to buoyancy, pushing the liquid sideways where liquid film zone starts to develop. In the falling liquid film region, the liquid moves downwards with velocity $\left(U_{L F}\right)$, and decreasing liquid film thickness $\left(\delta_{L F}\right)$. Once a balance between the gravitational and the friction forces is reached, a constant terminal liquid film velocity and thickness is developed. In the Taylor bubble wake region, the falling liquid film starts to plugs into the liquid slug ending with highly mixing zone in the wake structure of the bubble.

Moreover, Figure 3 gives further validation to the numerical code by showing a comparison between the numerical and experimental of Taylor bubble shape in the nose region, which is an essential feature as discussed by Araújo et al. (2013b). It can be seen that the simulation predicts well the experimental data.

Inaddition, Figure 4 shows a direct comparison for the resulting numerical velocity field in three different regions: Taylor bubble nose region, liquid film region, and wake region with the experimental work of Nogueira at al. (2006a\&b) in fixed reference frame (FRF). The axial velocity is plotted in dimensionless form $\left(u / U_{T B}\right)$ and $(x / D)$ refers to point placed in different axial iso-surfaces according to the region examined. The simulation results showed accepted matching with the experimental results in the different regions examined. Adding to this, the numerical axial velocity profile in the liquid film region shows good matching with both the experimental results and the theoretical velocity profile given by Brown (1965) (equation (12)).

$$
u_{z}=\frac{g}{v}\left[\frac{R^{2}-r^{2}}{4}-\frac{(R-r)^{2}}{2} \ln \frac{R}{r}\right]
$$

Furthermore, Table 3 shows the numerical, experimental, and theoretical values for some of the main hydrodynamic characteristics of the experimental validation case and their respective 
deviations. The value of $F r_{U_{T B}}$ shows deviation of $7.80 \%$ compared to experimental value measured by Nogueira et al. (2006a) . It also shows good agreement when compared with experimental and theoretical correlations of Wallis (1969) (equation (9)), and Viana et al. (2003) whose theoretical correlation is given by:

$$
F r=\frac{0.34 /\left(1+\frac{3805}{E o^{30.6}}\right)^{0.58}}{\left(1+\left(\left(\frac{R_{G}}{31.08}\right)\left(1+\frac{778.76}{E o^{1.96}}\right)^{-0.49}\right)^{-1.45\left(1+\frac{7.22 * 10^{13}}{E o^{9.93}}\right)^{0.094}}\right)^{0.74\left(1+\frac{7.22 * 10^{13}}{E o^{9.93}}\right)^{-0.094}}}
$$

where $R_{G}=\sqrt{D^{3} g\left(\rho_{L}-\rho_{G}\right) \rho_{L}} / \mu_{L}$

For the flow in liquid film region, three important parameters are discussed: liquid film thickness $\left(\delta_{L F}\right)$, wall shear stress $\left(\tau_{W}\right)$, and maximum liquid film velocity $\left(U_{L F}\right)$. Firstly, the values of $\delta_{L F}$, and $\tau_{W}$ shows good matching with both the experimental data of Nogueira et al. (2006a) and the theoretical predictions of Brown (1965). Brown (1965) equation for $\delta_{L F}$ prediction is given by equation (10), while the prediction for $\tau_{W}$ is given by:

$$
\tau_{W}=\rho_{L} g\left[\frac{R}{2}-\frac{\left(R-\delta_{L F}\right)^{2}}{2 R}\right]
$$

Secondly, the value of the third parameter $\left(U_{L F}\right)$ is as well close to experimental value. Furthermore, for the flow in the wake region, two main parameters namely: $L_{w} / D$, and $V_{w} / D^{3}$ are used to characterise the wake structure. The deviation with experimental values is quite large between $42 \%$ and $48 \%$ which is clarified by Araújo et al. (2013b) by the fact that the experimental technique did not account for the wake in the concave bottom at the rear of Taylor bubble. However, smaller deviations are established when comparing with the experimental correlations developed by Campos and De Carvalho (1988), which is given by:

$$
\begin{gathered}
\frac{L_{w}}{D}=0.30+1.22 \times 10^{-3} N_{f} \text { for } 100<N_{f}<500 \\
\frac{V_{w}}{D^{3}}=7.5 \times 10^{-4} N_{f} \text { for } 100<N_{f}<500
\end{gathered}
$$

The present study investigates the effects of density ratio $\left(\Gamma_{\rho}\right)$, viscosity ratio $\left(\Gamma_{\mu}\right)$, and the bubble size to the pipe diameter $\left(L_{T B} / D\right)$ on the hydrodynamic characteristics of the rise of single Taylor bubble in stagnant liquid t support previous numerical work and experimental 
work in literature. Cases 1 to 3 in Table 1 clearly emphasises that the density ratio has almost no effect on the dynamics of Taylor bubbles. The density ratio has minimal effect on liquid film thickness, maximum the velocity of liquid film, maximum wall shear stress, wake length and wake volume. The simulation results as well agree with the numerical result of Kang et al. (2010). For the viscosity ratio effect, three cases denoted by cases 3, 4, and 5 are simulated with viscosity ratios of $66.7,667$, and 6674 , respectively. Referring to Table 1 , it is also concluded that the viscosity ratio $\left(\Gamma_{\mu}\right)$ has minimal effect on the dynamics of Taylor bubbles including as well the liquid film thickness, maximum velocity of liquid film, maximum wall shear stress, wake length and wake volume. In conclusion, the simulated cases 1 to 6 have almost the same values of $R e_{U_{T B}}$, and $E o$, which is 24.34, and 66, respectively. Thus, the simulation results further assist the conclusion made by Lu and Prosperetti (2008) and Kang et al. (2010) that the both density ratio $\left(\Gamma_{\rho}\right)$, and viscosity ratio $\left(\Gamma_{\mu}\right)$ have a negligible effect on the dynamics of Taylor bubbles. Lastly, to explore the effect of $L_{T B} / D$, four cases are simulated denoted by cases 7 to 10 in Table 1 corresponding to $L_{T B} / D$ of $2,3,4$, and 10 , respectively. It can be also concluded that $L_{T B} / D$ as well has minimal effect on the dynamics of Taylor bubbles. Table 1 shows that these four cases has almost the same value of $F r_{U_{T B}}$ which agrees well with the conclusion of Kawaji et al. (1997) that the bubble length has no effect on the bubble terminal speed and subsequently no effect on Froude number $\left(F r_{U_{T B}}\right)$.

Further conclusion indicates that the validation results, in addition to the validation given by Massoud et al. (2016), where four cases based on the experimental work of Campos and De Carvalho (1988) are simulated and show good agreement when compared with both experimental and numerical data, illustrate that the numerical code is capable of simulation of Taylor bubble rising through stagnant liquid with high satisfaction degree of results. The problem can now be treated in terms of three main dimensionless groups, given by:

$$
F r_{U_{T B}}=\frac{U_{T B}}{\sqrt{g D}}=f\left[E o=\frac{g \rho_{L} D^{2}}{\sigma}, R e_{U_{T B}}=\frac{\rho_{L} U_{T B} D}{\mu_{L}}\right]
$$

In the following section, the effect of these core dimensionless groups that govern the present problem with the guidelines of the order of magnitude analysis are examined on the developed Taylor bubble shape, Taylor bubble rises velocity, flow in the liquid film and flow into the wake region. 


\subsection{Taylor bubble shape}

In this section, the effect of the main dimensionless groups that govern the present problem given by relation (16) is discussed. This includes representing the final shape of the developed Taylor bubble, the flow field around it (streamlines), and the Taylor bubble shape profile for each of the dimensionless groups examined.

\subsubsection{Effect of Reynolds number}

In literature, most of the studies done on dynamics of Taylor bubble rising through stagnant liquid highlight the major effect of inverse viscosity number or Archimedes number without considering the significant effect of Reynolds number. In this section ten cases namely: cases 11 to 20 in Table 1 are simulated to investigate the significant effect of $R e_{U_{T B}}$ on the dynamics of Taylor bubble. Figure 5 demonstrates the effect of $R e_{U_{T B}}$ number on the final shape of the developed Taylor bubble and the flow field for cases $11,13,15$, and 18 with $R e_{U_{T B}}$ values corresponding to $12,46,80$, and 131 , respectively. It can be shown that $R e_{U_{T B}}$ has prodigious effect on the final shape of bubble, as indicated in Figure 5. Particularly, for low values of $R e_{U_{T B}}$, the viscous forces of liquid phase surrounding the bubbles are high enough to encumber the rise of the Taylor bubble, and hence the terminal bubble velocity will be at its lowest values (lowest $F r_{U_{T B}}$ ), as indicated in Table 1. The increase in $R e_{U_{T B}}$ increases the velocity of Taylor bubble. It can be concluded from Table 1 that for $R e_{U_{T B}}$ values approximately above $80, F r_{U_{T B}}$ is almost the same which is in agreement with the experimental conclusions of Wallis (1969). It can also be concluded from Figure 5, that the high viscous forces enhance the elongation of the terminal developed Taylor bubble. The gradual increase in $R e_{U_{T B}}$ increases the concavity of the rear of Taylor bubble which is in good agreement with the experimental observation of Goldsmith and Mason (1962) that the rear of Taylor bubbles is characterized by being flat or concave when the flow is not viscosity dominated, and oblate spheroid when it is viscosity dominated. The shape of the rear of Taylor bubble and its transition critical criteria is discussed in details in section 4.6.

It is also concluded from Figure 5, that $R e_{U_{T B}}$ has significant effect on wake development. For low values of $R e_{U_{T B}}$, the liquid from the liquid film region expands directly and smoothly over the Taylor bubble bottom which is noticed by parallel streamlines in the wake region. Increasing the values of $R e_{U_{T B}}$, the Taylor bubble becomes wider in size squeezing the liquid 
film region that subsequently increases the velocity of the trailing liquid plugging in to the Taylor bubble bottom. This leads to the development of circulatory rear of vortices as liquid plugs into the Taylor bubble bottom. The scale and intensity of the vortex increases with higher values of $R e_{U_{T B}}$. In addition, Figure 6 shows the effect of $R e_{U_{T B}}$ on the bubble shape profile where it is clearly seen that the increase in $R e_{U_{T B}}$ causes the bubble nose to becomes less slender, and reduces the thickness of the developed liquid film.

\subsubsection{Effect of Eötvös number}

Eötvös number $(E o)$ represents the effect of buoyancy and surface tension forces which are two of the significant forces acting on Taylor bubbles. In order to investigate the effect of $E O$ number on the dynamics of Taylors bubble rising through stagnant liquids, 21 cases namely case 21 to case 42 in Table 1 are simulated. This covers wide range of Eo varying from 6-700. Figure 7 shows the effect of Eo on the final shape of the developed Taylor bubble and the flow field for cases 22, 25, 28 and 32 with Eo values corresponding to 10, 66, 100 and 160, respectively. At low values of $E o$, the surface tension forces are high enough to maintain any distortion at the gas-liquid interface. The bubble is noticed to have prolate spheroidal nose and oblate spheroid bottom. The increment in the surface tension increases the curvature of the bubble nose, and subsequently increases the liquid film thickness. Hence, the velocity of fully developed falling liquid film decreases.

Regarding the rear of the bubble, the increase in Eo leads to increase in inertial forces which is seen as values of $F r_{U_{T B}}$ increases. The increase in $E o$ also significantly affects the rear of bubble by gradually turning the bottom shape from convex or flat into concave structure, as indicated in Figure 7. This causes wakes to be developed at the rear of the bubble, and hence wake length and volume increases with the increase in Eo values, as indicated in Table 1. This has similar trend as that shown in Figure 5 exploring the effect of $R e_{U_{T B}}$. At certain critical value of $E o$, the further increase in Eo with its corresponding deficiency of surface tension results in deformation at gas-liquid interface. The shape of the bubble's rear turns from concave into wave and subsequently into breaking up. The breaking up concept is characterized by very unstable phenomena that occurs at the rear of the bubble and is noticed by the small bubbles shedding off from Taylor bubble into the wake region. Higher values of Eo, cause the gasliquid interface to lose its structure and strong breaking up concept is noticed (Morgado et al., 2016). A phase diagram map is discussed later in section 4.6 that describes the interesting 
phenomena that occur at the rear of Taylor bubbles which is strongly affected by surface tension, and inertia forces.

Furthermore, Figure 8 shows the effect of $E o$ on the bubble shape profile for different selected cases from Table 1. The increase in Eo increases the bluntness of the nose of the bubble, decreases the flatness of the bubble tail, and increment the liquid film thickness. This conclusion refutes that of Kang et al. (2010) that Eo has no effect on the dynamics at bubble nose, and liquid film thickness, but agrees with the conclusion of Taha and Cui (2006) and Zheng et al. (2007) which entails that $E o$ increases the degree of prolateness of the Taylor bubble nose.

In conclusion, $E o$, and $R e_{U_{T B}}$ significantly control the developed shape of Taylor bubble. The results shows that the surface tension forces are significant with low values of $E o$, while the large contribution of $R e_{U_{T B}}$ on dynamics of Taylor bubble is noticed with higher values of $R e_{U_{T B}}$. These conclusions agree well with the results of order of magnitude analysis discussed earlier in section 2. In the following section, the role of these dimensionless groups on the Taylor bubble rise velocity is introduced.

\subsection{Taylor bubble rise velocity}

The Taylor bubble rise velocity $\left(U_{T B}\right)$ is one of the main hydrodynamic features used for the description of two phase slug flow. In this section, a detailed discussion on Taylor bubble terminal velocity is introduced. Based on the discussion given in section 2 , it can be concluded that the terminal bubble velocity $\left(U_{T B}\right)$ is mainly governed by viscosity, surface tension, buoyancy and inertia forces. In literature, various studies either theoretical and/or experimental are done to account for the terminal bubble velocity. A good review for the main correlations for $F r_{U_{T B}}$, to account for bubble terminal velocity, starting from the theoretical investigation of Dumitrescu (1943) and ending with the resent study of Kurimoto et al. (2013) and is given by Morgado et al. (2016).

Based on relation (16), and on the cases simulated in Table 1, a proposed correlation to estimate $F r_{U_{T B}}$ that depends mainly on $E o$ and $R e_{U_{T B}}$ is developed, given by: 


$$
\begin{aligned}
& F r=\frac{U_{T B}}{\sqrt{g D}} \\
&=0.0359-0.3596 E o-0.7067 R e_{U_{T B}}+0.5801 E o^{2}-1.014 E o R e_{U_{T B}}+0.3447 E o^{3} \\
& \quad+1.594 E o^{2} R_{U_{T B}}-0.1931 E o^{4}+0.9647 E o^{3} R e_{U_{T B}}-0.001814 E o^{5} \\
& \quad-0.5481 E o^{4} R_{U_{T B}}
\end{aligned}
$$

Additionally, Figure 9 shows that the values obtained from the proposed correlation fit quite well with the behaviour of other well-known correlations from literature for different domains. Values predicted from Viana et al. (2003) correlations, and values from the recent correlation of Kurimoto et al. (2013) are added to Figure 9 for comparison purposes. It can be seen that the proposed correlation agrees well with a wide range of correlations with a maximum deviation of $\pm 10 \%$. In general, there is a proper matching between the data, especially in surface tension dominant domain. However, in inertia dominant domains with high values of Eo, the proposed correlation predicts the correlation of Viana et al. (2003). The only explanation is most probable to be a numerical problem for situations of high inertial forces as pointed out by Araújo et al. (2012). In brief, the proposed correlation shows an accepted behavior with other correlations with maximum deviation $\pm 10 \%$.

\subsection{Flow in liquid film}

The flow in the liquid film is investigated by characteristics associated with three key features: the dimensionless developed liquid film thickness $\left(\delta_{L F} / D\right)$, the dimensionless velocity of the liquid film $\left(U_{L F} / U_{T B}\right)$ and the dimensionless wall shear stress $\left(\frac{\tau_{W}}{\rho_{L} g D}\right)_{\max }$. This section will discuss the effect of the main dimensionless parameters, given in section 2 , on these three key features characterizing the flow in the liquid film.

\subsubsection{Liquid film velocity and thickness}

Figure 9 represents the effect of $R e_{U_{T B}}$ on the dimensionless normalized thicknesses and velocity of falling liquid film along the Taylor bubble length. At low values of $R e_{U_{T B}}$, the liquid film thickness $\left(\delta_{L F} / D\right)$ decreases with the increase in the dimensionless distance measure from bubble nose $(x / D)$ until it reaches a constant thickness at around $x / D=1$. At that point, a balance between the gravitational and friction forces is reached, and hence a constant liquid film thickness and velocity is established. However, the dimensionless velocity of the liquid film $\left(U_{L F} / U_{T B}\right)$ changes contrarily. The increase in $R e_{U_{T B}}$ diminishes the long slender shape of Taylor bubble and turns it into shorter and flatter bubbles which in turns reduces $\left(\delta_{L F} / D\right)$ 
(Kang et al., 2010). In addition, the higher viscosity of the surrounding liquid at low values of $R e_{U_{T B}}$ increment the shear stress in the liquid, thus, the momentum diffusion opposes the liquid flowing from the liquid film into the bubble wake region (Zheng et al., 2007). Therefore, the increase in $R e_{U_{T B}}$ increases the dimensionless velocity of the liquid film $\left(U_{L F} / U_{T B}\right)$.

Finally, the effect of $E o$ on the dimensionless normalized thicknesses and velocity of falling liquid film along the Taylor bubble length is given in Figure 11. As discussed earlier, the increase $E o$ affects the curvature of the bubble nose, thus increases $\left(\delta_{L F} / D\right)$, increases stabilization length (distance needed for formation of fully developed falling liquid film), and finally increases $U_{L F}$. However, the dimensionless velocity of the liquid film $\left(U_{L F} / U_{T B}\right)$ decreases with the increment in $E o$ due to the fact that the inertia forces are increased leading to increment in $U_{T B}$ values. It is concluded from Figure 11 that $\left(\delta_{L F} / D\right)$ and $\left(U_{L F} / U_{T B}\right)$ are affected with the increase in Eo till $E o \leq 66$, where further increase in Eo shows almost no effect on the flow in the liquid film.

In conclusion, it should be pointed out that both of $\left(\delta_{L F} / D\right)$, and $\left(U_{L F} / U_{T B}\right)$ are strongly dependent on $E o$, and $R e_{U_{T B}}$. This conclusion contradicts those made by: Kang et al. (2010): the liquid film thickness is only dependent on Archimedes number $\left(A r=N_{f}{ }^{2}\right)$, and that of Araújo et al. (2012): the liquid film thickness is function of $N_{f}$, and $M$.

\subsubsection{Wall shear stress distribution}

If the two-phase slug flow problem is involved in heat or mass transfer, then the wall shear stress becomes a primary significant hydrodynamic parameter. This process is often referred to as slug flow-induced corrosion (Zheng and Che (2006); Zheng and Che (2007); Zheng et al. (2007) and Araújo et al. (2012)). The main problems result from slug flow corrosion are: pipeline damage, decrease pipe lifetime and may lead to the shutdown of the pipeline.

Figure 12 shows the wall shear stress distribution along the Taylor bubble length for different $R e_{U_{T B}}$. For low values of $R e_{U_{T B}}$, the wall shear stress distribution starts with an increase in the wall shear stress near the bubble nose then it reaches a maximum positive value with the formation of a constant liquid film characteristics (thickness and velocity). The wall shear stress then starts to decrease till it reaches zero value in the bubble tail or wake region.

The increase in $R e_{U_{T B}}$, results in less the viscous liquid surrounding the Taylor bubble, that subscribes to decrement in wall shear stress. This conclusion agrees well with that made by 
Taha and Cui (2006). On the one hand, the dimensionless wall shear stress in the nose region is not affected by the increase in $R e_{U_{T B}}$, on the other hand, the plateau behaviour at the developed liquid film is shortened with the increase in $R e_{U_{T B}}$. This occurs as a result of the shape in Taylor bubble shape which is characterized by being a long slender that turns into shorter and flatter bubbles with the increase in $R e_{U_{T B}}$. Additionally, it should be pointed out that the effect of increase in $R e_{U_{T B}}$ on the bubble wake region is seen as jump in dimensionless wall shear values that increases with higher values of $R e_{U_{T B}}$; this further assists the conclusion made by Kang et al. (2010). A further validation for the flow in liquid film region is given in Figure 13, where a comparison takes place between the numerical results for dimensionless wall shear stress, and $\delta_{L F} / D$, and the theoretical values by Brown (1965). It is clear that the numerical results strongly correspond with the theoretical data.

Finally, the effect of $E o$ on the distribution of the dimensionless wall shear stress along the Taylor bubble is given in Figure 14. Generally, for most values of Eo, the distribution is almost the same, which starts with increase in wall shear stress near the bubble nose, then a constant value is reached at the developed liquid film, followed by reduction in dimensionless wall shear stress near the bubble tail. As indicated in Figure 14, lower values of Eo possess different distribution with noticeable peak value in dimensionless shear stress right before the Taylor bubble rear. This is due to the sharp flat and convex shape of the bubble attained at lower values of Eo as discussed in section 4.3.2, which coincides with Araújo et al. (2012).

In conclusion, the numerical results show that the dimensionless wall shear stress is dependent on both $E o$, and $R e_{U_{T B}}$ which again contradicts the conclusion made by Kang et al. (2010) that the wall shear stress is only function of $A r$, and supports Araújo et al. (2012) conclusion in different scenario. Subsequently, a correlation based on the numerical results for all simulated cases in Table 1 for dimensionless maximum wall shear stress is suggested, given by:

$$
\begin{aligned}
& \left(\frac{\tau_{W}}{\rho_{L} g D}\right)_{\max } \\
& =0.242+0.238 E o+0.5544 R e_{U_{T B}}-0.1196 E o^{2}+1.037 E o R e_{U_{T B}}+0.5294 R e_{U_{T B}}^{2} \\
& -2.818 e^{-05} E o^{3}-0.3202 E o^{2} R_{U_{T B}}+1.083 E o R e_{U_{T B}}^{2} \\
& -0.0008579 R e_{U_{T B}^{3}}^{3}
\end{aligned}
$$

Figure 15 illustrates the present numerical results, and values obtained from proposed correlation given in equation (18) for the maximum dimensionless wall shear stress along the Taylor bubble length for different values of Eo (cases 21 to 42 in Table 1). It is obvious that 
the correlation matches the simulation data to a considerable extent. For comparison issues, the theoretical prediction given by Brown (1965) (equation (14)), and predictions using Kang et al. (2010) correlation (equation (19)) are added to Figure 15.

$$
\left(\frac{\tau_{W}}{\rho_{L} g D}\right)_{\max }=-0.02 \log _{10} A r+0.2
$$

It can be seen from Figure 15, that the suggested correlation matches well with the theoretical predictions calculated by Brown (1965) with very small deviations. However, there is an exception for that proper matching for small values of Eo. Generally, these cases with low values of $E o$ (especially around 6) possess low values of $U_{\text {ТВ }}$ with almost non-moving bubbles. These cases are more sensitive to numerical errors as clarified by (Araújo et al., 2012, Zheng et al., 2007)

It should be pointed out that $R e_{U_{T B}}$ is not constant for these selected cases, and its values are indicated in Table 1. Similarly, as discussed before for the liquid film thickness, the dimensionless wall shear stress is function of both $E o$, and $R e_{U_{T B}}$, and not only function of $A r$ as concluded by Kang et al. (2010). This conclusion completely agrees with Araújo et al. (2012) that dimensionless wall shear stress depends on $E o$, and $M$, but with different scenario as discussed in section 2.

In conclusion, the flow in the liquid film is considerably affected by $E o$, and $R e_{U_{T B}}$. It should be pointed out that both $E o$, and $R e_{U_{T B}}$ significantly control the wall shear stress distribution which in turns control the corrosion process related to two-phase flow which is known as slug flow induced corrosion. In the next section, the contribution of these dimensionless groups on the flow in the wake region is discussed.

\subsection{Flow in wake region}

The wake structure is one of the vital hydrodynamic characteristics of slug flow systems, especially in describing the interaction and coalescences between successive Taylor bubbles and in modelling process (Araújo et al., 2012). Understanding the mechanism by which the wake region is developed is essential prior to introducing the simulation results for flow in wake region. The annular falling film from the liquid film region plugs into the rear of the Taylor bubble and creates mixing and recirculation zone which is known by bubble wake. The intensity and size of the recirculation vortices in the wake region depend on the properties of 
the surrounding liquid, especially its viscosity as indicated by the experimental work of Campos and De Carvalho (1988). As discussed previously in section 2, Campos and De Carvalho (1988) conclude three flow patterns for the wake depending on the inverse viscosity number, $N_{f}$. In the present study, most of the cases bump into closed axisymmetric laminar wake.

Stimulated by the work of Morgado et al. (2016), and based on the simulated cases given in Table 1, phase diagram of the presence and nature of wake, and of the shape of the rear Taylor bubble are presented in Figure 16, and Figure 17, respectively. The diagrams are given in terms of $E o$, and $R e_{U_{T B}}$, based on the problem formulation given in section 1. Throughout the present study, only two kinds of wake are observed: either closed axisymmetric wake or no wake. For the shape of rear of Taylor bubble, as discussed earlier in section 4.3.2, when the surface tension is significantly reduced, the gas-liquid interface is easily deformed and the shape of Taylor bubble rear becomes unstable. Stable bubble shape is classified in to concave, convex, or flat bubbles. However, unstable bubble wakes are either wavy or breaking up bubbles. Figure 17 showed the type of bubble rear shape for all data simulated which strongly corresponds with Kang et al. (2010) and Morgado et al. (2016) which conclude that the sudden elongation in the bubble tail, based on investigating the effect of Eo on the dynamics of Taylor bubbles, is around unity which corresponds to Eo $>250$. Referring to cases 21 to 42 in Table 1, it is observed that the gas-liquid interface starts to become unstable approximately at $E o>200$. Numerical solutions with either wavy or breaking up bubble wakes and cases with small bubble detachment required extremely refined meshes to be accurate. Figure 18 illustrates an example for this unstable nature of gas-liquid interface for case 36 in Table 1.

The wake region is investigated by two main parameters, namely dimensionless wake length $\left(L_{W} / D\right)$, and dimensionless wake volume $\left(V_{w} / D^{3}\right)$. One of the main correlations used to predict these parameter is that of Campos and De Carvalho (1988) which is given by equation (15). Recently, Araújo et al. (2012) suggested equation for the dimensionless wake length, $L_{W} / D$, and dimensionless wake volume $\left(V_{w} / D^{3}\right)$ function in $E o$, and $M$, given by:

$$
\begin{aligned}
& \frac{L_{W}}{D}=\frac{1}{4} \times\left[0.555-7.793 \times 10^{3} \ln (M)\right] \times \ln \left(\frac{E o^{3}}{M}\right)-2.133+8.046 \\
& \quad \times 10^{-2} \ln (M) \\
& \frac{V_{W}}{D^{3}}= 1.365 \times 10^{-1}\left(\frac{L_{W}}{D}\right)^{2}+2.176 \times 10^{-1}\left(\frac{L_{W}}{D}\right)-2.91910^{-2}
\end{aligned}
$$


Following the same procedure of Araújo et al. (2012) for measuring $L_{W} / D$, and $V_{W} / D^{3}$, Table 1 gives the simulation results for these two parameters for all cases under investigation.

As discussed earlier, the effect of $R e_{U_{T B}}$ on the flow in the wake region is noticed by the change in the shape of rear of the Taylor bubble from flat into convex. In addition, the increase in $R e_{U_{T B}}$ decreases the liquid film thickness thus squeezing liquid in narrower region. As a result, the intensity and size of the wake increases, which is noticed by the increment of $L_{W} / D$ and $V_{W} / D^{3}$ as indicated in Figure 19. Furthermore, A similar scenario is noticed for the increase in $E o$, for cases 21 to 42 in Table 1 , that results in increase in $L_{W} / D$, and $V_{W} / D^{3}$ values. It should be pointed out that for cases 36 to 42 in Table $1, L_{W} / D$ and $V_{W} / D^{3}$ are calculated as average values once the solution is converged and most of the hydrodynamics characteristics investigated are developed. This is because the developed bubble shape is unstable which is either wavy or breaking up. A good matching between simulation results for $L_{W} / D$, and $V_{W} / D^{3}$, and the experimental correlation given by Campos and De Carvalho (1988) is shown in Figure 19.

Also, Table 4 gives a comparison of the simulation results, experimental data, and correlations from literature for $L_{W} / D$, and $V_{W} / D^{3}$ for validation of the present code regarding flow in wake region. Two simulation cases based on the experimental work of Campos and De Carvalho (1988) with $E o$ in range of 64 , and $R e_{U_{T B}}$ in range of 56-107, are simulated. It can be concluded from Table 4, that numerical results show good matching with other correlations in literature, experimental correlation of Campos and De Carvalho (1988) and numerical correlation of Araújo et al. (2012).

In conclusion, the flow in the wake region is significantly affected by both $E o$, and $R e_{U_{T B}}$ which can be clarified by the change in corresponding dimensionless wake length and volume. Additionally, the results revealed that both $L_{W} / D$ and $V_{W} / D^{3}$ are mainly dependent on $E o$, and $R e_{U_{T B}}$, which again agrees with the predictions of Kang et al. (2010), and contradicts Araújo et al. (2012) conclusion with different point of view based on the significance of Reynolds number $\left(R e_{U_{T B}}\right)$ rather than Morton number $(M)$.

\section{Conclusions}

In this paper, a complete dimensionless analysis of single Taylor bubble rising through a vertical stagnant Newtonian liquid problem is performed followed by the order of magnitude analysis of the equations of motion. The main conclusion is that Froude number $\left(F r_{U_{T B}}\right)$, is 
function of Eötvös number $(E o)$, Reynolds number $\left(R e_{U_{T B}}\right)$, density ratio $\left(\Gamma_{\rho}\right)$, viscosity ratio $\left(\Gamma_{\mu}\right)$ and $L_{T B} / D$. The effect of density ratio $\left(\Gamma_{\rho}\right)$, viscosity ratio $\left(\Gamma_{\mu}\right)$ and the bubble size to the pipe diameter $\left(L_{T B} / D\right)$ are examined for the sake of supporting other previous experimental and numerical works in the literature.

Based on the dimensionless analysis, the hydrodynamic characteristics of single Taylor bubble rising through vertical stagnant Newtonian liquid is investigated using the volume-of-fluid (VOF) methodology implemented in the computational fluid dynamics software package, ANSYS Fluent (Release 15.0), with particular focus on the sole dimensionless parameters: Froude number $\left(F r_{U_{T B}}\right)$, Reynolds number $\left(R e_{U_{T B}}\right)$ and Eötvös number $(E o)$. The results are divided into four sections: Taylor bubble shape, Taylor bubble rise velocity, flow in the liquid film region and flow in the wake region. The numerical results predicted the problem effectively as they were validated by testing some of the selective cases against both theoretical and experimental data in the literature.

Based on the numerical results and using guidelines from order of magnitude analysis, correlation to estimate Taylor bubble rise velocity $\left(U_{T B}\right)$ as a function in only $E o$, and $R e_{U_{T B}}$ is proposed and shows good prediction when compared with other well-known correlations in literature, especially with Viana et al. (2003) correlation.

\section{Detailed Hydrodynamics:}

Eo showed significant effect on all hydrodynamic features of Taylor bubbles. The increment in surface tension increases the curvature of the bubble nose, increases the liquid film thickness, decreases the dimensionless velocity of fully developed falling liquid film, and finally increases wake intensity and size. For the flow in the liquid film, the numerical results are compared with the theoretical predictions given by Brown (1965) and establishing a strong correspondence.

$R e_{U_{T B}}$ shows contribution similar to $E o$ number. The developed Taylor bubble shape changes from long slender shape into shorter and flatter bubbles with the increase in $R e_{U_{T B}}$; this results in reduction in liquid film thickness.

Additionally, the wall shear stress was examined under the effect of both $E o$ and $R e_{U_{T B}}$. The increase in $R e_{U_{T B}}$ results in less viscous effect in the liquid surrounding the Taylor bubble that subscribes to decrement in wall shear stress. The wall shear stress increases with $E o$, however it should be pointed out that lower values of Eo possesses different distribution for the wall shear stress with noticeable peak value right before the Taylor bubble rear due to the sharp flat 
and convex shape of the bubble attained at lower values of Eo. Based on the numerical results for wall shear stress, a proposed correlation for maximum wall shear stress is developed and predicts results favourably matching with the theoretical predictions of Brown (1965).

Furthermore, for the wake region, a phase diagram showing the presence and nature of wake, and of the shape of the rear Taylor bubble is illustrated. Unstable bubbles are developed at Eo above 200 which are characterized by presence of small bubbles shedding off from main Taylor bubble into wake region.

Finally, it can be concluded that the developed numerical results agree well with the order of magnitude analysis. For instance, the order of magnitude analysis has shown that, in order for Reynolds number for the major viscous terms to remain intact, it should be of order $\left(\frac{\mathrm{L}_{\mathrm{TB}}}{\mathrm{D}}\right)$, which means relatively large values. The numerical result agrees well with that showing the significance of the larger values of Reynolds number on the dynamics of Taylor bubble including bubble shape, terminal velocity, flow in the liquid film and flow in the wake region.

\section{Acknowledgements}

Results were obtained using the EPSRC funded ARCHIE-WeSt High-Performance Computer (www.archie-west.ac.uk). EPSRC grant no. EP/K000586/1.

\section{References}

AKAGAWA, K. \& SAKAGUCHI, T. 1966. Fluctuation of Void Ratio in Two-Phase Flow: 2nd Report, Analysis of Flow Configuration Considering the Existence of Small Bubbles in Liquid Slugs. Bulletin of JSME, 9, 104-110.

ARAÚJO, J., MIRANDA, J. \& CAMPOS, J. 2013a. Flow of two consecutive Taylor bubbles through a vertical column of stagnant liquid-A CFD study about the influence of the leading bubble on the hydrodynamics of the trailing one. Chemical Engineering Science, 97, 16-33.

ARAÚJO, J., MIRANDA, J. \& CAMPOS, J. 2013b. Simulation of slug flow systems under laminar regime: Hydrodynamics with individual and a pair of consecutive Taylor bubbles. Journal of Petroleum Science and Engineering, 111, 1-14.

ARAÚJO, J., MIRANDA, J., PINTO, A. \& CAMPOS, J. 2012. Wide-ranging survey on the laminar flow of individual Taylor bubbles rising through stagnant Newtonian liquids. International Journal of Multiphase Flow, 43, 131-148.

BRACKBILL, J., KOTHE, D. B. \& ZEMACH, C. 1992. A continuum method for modeling surface tension. Journal of computational physics, 100, 335-354.

BROWN, R. 1965. The mechanics of large gas bubbles in tubes: I. Bubble velocities in stagnant liquids. The Canadian Journal of Chemical Engineering, 43, 217-223. 
BUGG, J., MACK, K. \& REZKALLAH, K. 1998. A numerical model of Taylor bubbles rising through stagnant liquids in vertical tubes. International Journal of Multiphase Flow, 24, 271-281.

CAMPOS, J. \& DE CARVALHO, J. G. 1988. An experimental study of the wake of gas slugs rising in liquids. Journal of Fluid Mechanics, 196, 27-37.

CLANET, C., HÉRAUD, P. \& SEARBY, G. 2004. On the motion of bubbles in vertical tubes of arbitrary cross-sections: some complements to the Dumitrescu-Taylor problem. Journal of Fluid Mechanics, 519, 359-376.

CLARKE, A. \& ISSA, R. 1997. A numerical model of slug flow in vertical tubes. Computers \& fluids, 26, 395-415.

DESAMALA, A. B., DASAMAHAPATRA, A. K. \& MANDAL, T. K. 2014. Oil-Water TwoPhase Flow Characteristics in Horizontal Pipeline-A Comprehensive CFD Study.

DESAMALA, A. B., DASARI, A., VIJAYAN, V., GOSHIKA, B. K., DASMAHAPATRA, A. K. \& MANDAL, T. K. 2013. CFD simulation and validation of flow pattern transition boundaries during moderately viscous oil-water two-phase flow through horizontal pipeline. WASET J, 73, 1150-1155.

DIREITO, F., MORGADO, A., ROCHA, L., MIRANDA, J. \& CAMPOS, J. 2017. Experimental and numerical 3D study of a Taylor drop rising in a stagnant heavier liquid. Physics of Fluids, 29, 037109.

DUMITRESCU, D. T. 1943. Strömung an einer Luftblase im senkrechten Rohr. ZAMM Journal of Applied Mathematics and Mechanics/Zeitschrift $f$ ü $r$ Angewandte Mathematik und Mechanik, 23, 139-149.

FABRE, J. \& LINÉ, A. 1992. Modeling of two-phase slug flow. Annual review of fluid mechanics, 24, 21-46.

FLUENT, A. 2015. Theory Guide and User's Guide. Ansys Inc, USA.

FRÉCHOU, D. 1986. Etude de l'écoulement vertical ascendant à trois fluides en conduite verticale. (Doctoral dissertation).

FULFORD, G. D. 1964. The flow of liquids in thin films. Advances in Chemical Engineering, $5,151-236$.

GOLDSMITH, H. \& MASON, S. 1962. The movement of single large bubbles in closed vertical tubes. Journal of Fluid Mechanics, 14, 42-58.

HIRT, C. W. \& NICHOLS, B. D. 1981. Volume of fluid (VOF) method for the dynamics of free boundaries. Journal of computational physics, 39, 201-225.

ISSA, R. \& UBBINK, O. 1999. Numerical prediction of Taylor bubble dynamics using a new interface capturing technique. ASME Paper FEDSM99-7103, Proceedings of the third joint.

KANG, C.-W., QUAN, S. \& LOU, J. 2010. Numerical study of a Taylor bubble rising in stagnant liquids. Physical Review E, 81, 066308.

KAWAJI, M., DEJESUS, J. \& TUDOSE, G. 1997. Investigation of flow structures in vertical slug flow. Nuclear Engineering and Design, 175, 37-48. 
KURIMOTO, R., HAYASHI, K. \& TOMIYAMA, A. 2013. Terminal velocities of clean and fully-contaminated drops in vertical pipes. International Journal of Multiphase Flow, 49, 8-23.

LIBERZON, D., SHEMER, L. \& BARNEA, D. 2006. Upward-propagating capillary waves on the surface of short Taylor bubbles. Physics of fluids, 18, 048103.

LU, X. \& PROSPERETTI, A. 2008. A numerical study of Taylor bubbles. Industrial \& Engineering Chemistry Research, 48, 242-252.

MAO, Z.-S. \& DUKLER, A. 1990. The motion of Taylor bubbles in vertical tubes. I. A numerical simulation for the shape and rise velocity of Taylor bubbles in stagnant and flowing liquid. Journal of computational physics, 91, 132-160.

MASSOUD, E., XIAO, Q., TEAMAH, M. \& SAQR, K. 2016. Numerical Study of Hydrodynamic Characteristics of Gas-Liquid Slug Flow in Vertical Pipes. Journal of Applied Mechanical Engineering, 5.

MAYOR, T. S., PINTO, A. \& CAMPOS, J. 2007. Hydrodynamics of gas-liquid slug flow along vertical pipes in turbulent regime: a simulation study. Chemical Engineering Research and Design, 85, 1497-1513.

MORGADO, A., MIRANDA, J., ARAUJO, J. \& CAMPOS, J. 2016. Review on vertical gasliquid slug flow. International Journal of Multiphase Flow, 85, 348-368.

NDINISA, N., WILEY, D. \& FLETCHER, D. 2005. Computational fluid dynamics simulations of Taylor bubbles in tubular membranes: model validation and application to laminar flow systems. Chemical Engineering Research and Design, 83, 40-49.

NICKLIN, D., WILKES, J. \& DAVIDSON, J. 1962. Two-phase flow in vertical tubes. Trans. Inst. Chem. Eng, 40, 61-68.

NOGUEIRA, S., RIETHMULER, M., CAMPOS, J. \& PINTO, A. 2006a. Flow in the nose region and annular film around a Taylor bubble rising through vertical columns of stagnant and flowing Newtonian liquids. Chemical Engineering Science, 61, 845-857.

NOGUEIRA, S., RIETHMULlER, M., CAMPOS, J. \& PINTO, A. 2006b. Flow patterns in the wake of a Taylor bubble rising through vertical columns of stagnant and flowing Newtonian liquids: An experimental study. Chemical engineering science, 61, 71997212.

POLONSKY, S., SHEMER, L. \& BARNEA, D. 1999. The relation between the Taylor bubble motion and the velocity field ahead of it. International Journal of Multiphase Flow, 25, 957-975.

RAHIMI, R., BAHRAMIFAR, E. \& SOTOODEH, M. M. 2013. The Indication of Two-Phase Flow Pattern and Slug Characteristics in a Pipeline Using CFD Method.

RAZAVI, S. \& NAMIN, M. 2011. Numerical Model of Slug Development on Horizontal Twophase Flow.

SANTOS, T. S. M. M. 2007. Hydrodynamics of gas-liquid flows in slug flow regime. Doctoral dissertation, Universidade do Porto (Portugal), Universidade do Porto (Portugal).

SOUSA, R., RIETHMULLER, M., PINTO, A. \& CAMPOS, J. 2006. Flow around individual Taylor bubbles rising in stagnant polyacrylamide (PAA) solutions. Journal of nonnewtonian fluid mechanics, 135, 16-31. 
TAHA, T. \& CUI, Z. 2006. CFD modelling of slug flow in vertical tubes. Chemical Engineering Science, 61, 676-687.

VAN HOUT, R., GULITSKI, A., BARNEA, D. \& SHEMER, L. 2002. Experimental investigation of the velocity field induced by a Taylor bubble rising in stagnant water. International Journal of Multiphase Flow, 28, 579-596.

VIANA, F., PARDO, R., YANEZ, R., TRALLERO, J. L. \& JOSEPH, D. D. 2003. Universal correlation for the rise velocity of long gas bubbles in round pipes. Journal of Fluid Mechanics, 494, 379-398.

WALLIS, G. B. 1969. One-dimensional two-phase flow.

YAN, K. \& CHE, D. 2011. Hydrodynamic and mass transfer characteristics of slug flow in a vertical pipe with and without dispersed small bubbles. International journal of multiphase flow, 37, 299-325.

ZHENG, D. \& CHE, D. 2006. Experimental study on hydrodynamic characteristics of upward gas-liquid slug flow. International journal of multiphase flow, 32, 1191-1218.

ZHENG, D. \& CHE, D. 2007. An investigation on near wall transport characteristics in an adiabatic upward gas-liquid two-phase slug flow. Heat and mass transfer, 43, 10191036.

ZHENG, D., HE, X. \& CHE, D. 2007. CFD simulations of hydrodynamic characteristics in a gas-liquid vertical upward slug flow. International journal of heat and mass transfer, $50,4151-4165$.

\section{List of Tables}

Table 1- Simulation cases and their corresponding results.

Table 2- Mesh dependence test results, Eo=64, ReUTB=60, FrUTB=0.3409.

Table 3- Numerical, experimental, and theoretical values for some of the main hydrodynamic characteristics of experimental case based on work of Nogueira et al. (2006a\&b) with Eo=186, ReUTB=37.083, $\operatorname{FrUTB}=\mathbf{0 . 3 3 5 5}$, and their respective deviations.

Table 4- Numerical and experimental values of $\mathrm{LW} / \mathrm{D}$, and $\mathrm{VW} / \mathrm{D} 3$, and their respective deviations with respect to experimental data

\section{List of Figures}

Figure 1. Schematic representation of the computational domain and the main hydrodynamic features of a single Taylor bubble rising through stagnant liquid showing the different flow regions based on the definition of Reynolds number (Mayor et al., 2007), the initial and boundary conditions, the change from a fixed reference frame system (a) to a moving reference frame system (b). 
Figure 2. Numerical results of the Streamlines (left) and Velocity fields (right) of a rising Taylor bubble through stagnant liquid vertical pipe, $\mathrm{Eo}=186$, $\operatorname{ReUTB}=37.083$, FrUTB=0.3355 using moving reference frame (MRF).

Figure 3. The experimental and numerical shape of Taylor bubble in nose region- $x$ is the axial distance from bubble nose.

Figure 4. Numerical, experimental, and theoretical dimensionless axial velocity profile for three different regions: Taylor bubble nose region, liquid film region, and wake region in a fixed reference frame. Eo=186, ReUTB=37.083, FrUTB=0.3355.

Figure 5. Effect of ReUTB on the terminal shape of Taylor bubble, and streamlines representing the flow field. (a) Case (11) ReUTB =12, (b) Case (13) $\operatorname{ReUTB}=\mathbf{4 6}$, (c) Case (15) ReUTB =80, and (d) Case (18) ReUTB =131.

Figure 6. Effect of ReUTB on bubble shape profile- $x$ is the axial distance from bubble nose.

Figure 7. Effect of Eo on the terminal shape of Taylor bubble, and streamlines representing the flow field. (a) Case (22) Eo =10, (b) Case (25) Eo =66, (c) Case (28) Eo =100, and (d) Case (32) Eo =160.

Figure 8. Effect of Eo on bubble shape profile - $x$ is the axial distance from bubble nose.

Figure 9. Numerical results of UTB expressed in terms of FrUTB for a several Eo with corresponding values obtained from proposed correlation given in equation (17), and different correlations from literature for comparison. ReUTB varies from 2.6 to 25.3.

Figure 10. The effect of ReUTB on the dimensionless normalized thicknesses ( $\delta \mathrm{LF} / \mathrm{D})$ and dimensionless velocity of falling liquid film (ULF/UTB) along the Taylor bubble length- $\mathbf{x}$ is axial distance from bubble nose.

Figure 11. The effect of Eo on the dimensionless normalized thicknesses $(\delta \mathrm{LF} / \mathrm{D})$ and dimensionless velocity of falling liquid film (ULF/UTB) along the Taylor bubble length- $\mathbf{x}$ is axial distance from bubble nose.

Figure 12. Effect of ReUTB on the wall shear stress distribution ( $\tau W \rho L g D$ ) along Taylor bubble length - $\mathbf{x}$ is axial distance from bubble nose.

Figure 13. Variation of the dimensionless normalised thickness ( $\delta \mathrm{LF} / \mathrm{D})$ and dimensionless maximum wall shear stress ( $\tau$ W $\rho$ Lg D)max distribution along Taylor bubble length with ReUTB plotted with the theoretical prediction of Brown (1965) (equations (10), and equation (14)).

Figure 14. Effect of Eo on the wall shear stress distribution along Taylor bubble length - $x$ is axial distance from bubble nose, ReUTB varies from 2.6 to 25.

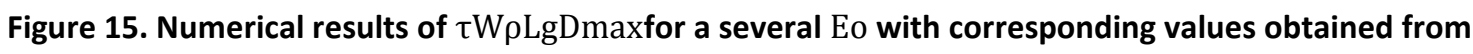
proposed correlation given in equation (18), theoretical prediction given by Brown (1965) (equation (14)), and predictions using Kang et al. (2010) correlation (equation (19)), for cases 21 to 42 in Table 1. 
Figure 16. Phase diagram of the presence and kind of wake of Taylor bubbles rising through vertical columns of stagnant liquid.

Figure 17. Phase diagram of the rear of Taylor bubble shape, expressed in terms of Eo, and ReUTB, of a Taylor bubbles rising through vertical columns of stagnant liquid.

Figure 18. Development of wake flow pattern of Taylor bubble rising vertical columns of stagnant liquid for case (36) with a time interval of $0.5 \mathrm{~s}: \mathrm{Eo}=250, \operatorname{ReUTB}=25.26$, and FrUTB $=0.3$.

Figure 19. Numerical results of dimensionless wake length (LW/D), and dimensionless wake volume (VW/D3) for cases 13 to 19 in Table 1. 
Table 1- Simulation cases and their corresponding results.

\begin{tabular}{|c|c|c|c|c|c|c|c|c|c|c|c|c|}
\hline \multicolumn{5}{|c|}{ Input Parameters } & \multicolumn{8}{|c|}{ Predicted Values } \\
\hline \multirow{2}{*}{$\begin{array}{c}\text { Case } \\
\text { No. }\end{array}$} & \multirow[b]{2}{*}{ Eo } & \multirow{2}{*}{$\Gamma_{\rho}=\frac{\rho_{L}}{\rho_{G}}$} & \multirow{2}{*}{$\Gamma_{\mu}=\frac{\mu_{L}}{\mu_{G}}$} & \multirow{2}{*}{$\left(\frac{\boldsymbol{L}_{T B}}{D}\right)_{i}$} & \multirow[b]{2}{*}{$F r_{U_{T B}}$} & \multirow[b]{2}{*}{$R e_{U_{T B}}$} & \multirow{2}{*}{$\left(\frac{\boldsymbol{L}_{T B}}{D}\right)_{p}$} & \multicolumn{3}{|c|}{ Flow in liquid film region } & \multicolumn{2}{|c|}{ Flow in wake region } \\
\hline & & & & & & & & $\frac{\delta_{L F}}{D}$ & $U_{L F_{\max }}$ & $\left(\frac{\tau_{W}}{\rho_{L} g D}\right)_{\max }$ & $L_{w} / D$ & $V_{w} / D^{3}$ \\
\hline \multicolumn{13}{|c|}{ Effect of density ratio $(\boldsymbol{\Gamma} \rho)$} \\
\hline 1 & 66 & $6 \mathrm{E}+01$ & $6.67 \mathrm{E}+03$ & 3 & 0.290 & 24.3 & 3.1 & 0.1250 & 0.1870 & 0.1074 & 0 & 0 \\
\hline 2 & 66 & $9.98 \mathrm{E}+02$ & $6.67 \mathrm{E}+03$ & 3 & 0.290 & 24.3 & 3.1 & 0.1243 & 0.1086 & 0.109 & 0 & 0 \\
\hline 3 & 66 & $2 \mathrm{E}+02$ & $6.67 E+03$ & 3 & 0.287 & 24.1 & 3.1 & 0.1246 & 0.1873 & 0.1084 & 0 & 0 \\
\hline \multicolumn{13}{|c|}{ Effect of density ratio $\left(\Gamma_{\mu}\right)$} \\
\hline 4 & 66 & $9.98 \mathrm{E}+02$ & $6.67 E+01$ & 3 & 0.288 & 24.2 & 3.12 & 0.1251 & 0.1848 & 0.1071 & 0 & 0 \\
\hline 5 & 66 & $9.98 \mathrm{E}+02$ & $6.67 \mathrm{E}+02$ & 3 & 0.289 & 24.3 & 3.1 & 0.1244 & 0.1863 & 0.1085 & 0 & 0 \\
\hline 6 & 66 & $9.98 \mathrm{E}+02$ & $6.67 \mathrm{E}+03$ & 3 & 0.290 & 24.3 & 3.1 & 0.1243 & 0.1086 & 0.109 & 0 & 0 \\
\hline \multicolumn{13}{|c|}{ Effect of $\mathbf{L}_{\mathrm{TB}} / \mathrm{D}$} \\
\hline 7 & 66 & $9.98 \mathrm{E}+02$ & $6.67 \mathrm{E}+03$ & 2 & 0.2898 & 24.3 & 2.14 & 0.1246 & 0.1083 & 0.1083 & 0 & 0 \\
\hline 8 & 66 & $9.98 \mathrm{E}+02$ & $6.67 \mathrm{E}+03$ & 3 & 0.2898 & 24.3 & 3.1 & 0.1243 & 0.1086 & 0.109 & 0 & 0 \\
\hline 9 & 66 & $9.98 \mathrm{E}+02$ & $6.67 \mathrm{E}+03$ & 4 & 0.2898 & 24.3 & 4.1 & 0.1244 & 0.1087 & 0.1087 & 0 & 0 \\
\hline 10 & 66 & $9.98 \mathrm{E}+02$ & $6.67 E+03$ & 10 & 0.2847 & 23.9 & 9.9 & 0.1232 & 0.1084 & 0.1084 & 0 & 0 \\
\hline \multicolumn{13}{|c|}{ Effect of Reynolds number $\left(\operatorname{Re}_{\mathrm{UTB}}\right)$} \\
\hline 11 & 66 & $9.98 \mathrm{E}+02$ & $6.67 \mathrm{E}+03$ & 3 & 0.246 & 12 & 3.04 & 0.138 & 0.1437 & 0.1188 & 0 & 0 \\
\hline 12 & 66 & $9.98 \mathrm{E}+02$ & $6.67 \mathrm{E}+03$ & 3 & 0.292 & 29 & 3.09 & 0.1183 & 0.1993 & 0.2350 & 0 & 0 \\
\hline 13 & 66 & $9.98 \mathrm{E}+02$ & $6.67 \mathrm{E}+03$ & 3 & 0.307 & 46 & 3.08 & 0.1063 & 0.1041 & 0.0948 & 0.3775 & 0.06779 \\
\hline 14 & 66 & $9.98 \mathrm{E}+02$ & $6.67 \mathrm{E}+03$ & 3 & 0.315 & 63 & 3.11 & 0.0982 & 0.2596 & 0.0882 & 0.5717 & 0.1305 \\
\hline 15 & 66 & $9.98 \mathrm{E}+02$ & $6.67 \mathrm{E}+03$ & 3 & 0.320 & 80 & 3.1 & 0.0922 & 0.2815 & 0.0831 & 0.6542 & 0.1786 \\
\hline 16 & 66 & $9.98 \mathrm{E}+02$ & $6.67 \mathrm{E}+03$ & 3 & 0.324 & 97 & 3.12 & 0.0875 & 0.2995 & 0.0791 & 0.7341 & 0.2212 \\
\hline 17 & 66 & $9.98 \mathrm{E}+02$ & $6.67 \mathrm{E}+03$ & 3 & 0.325 & 114 & 3.14 & 0.0822 & 0.3185 & 0.0788 & 0.8087 & 0.2571 \\
\hline 18 & 66 & $9.98 \mathrm{E}+02$ & $6.67 \mathrm{E}+03$ & 3 & 0.328 & 131 & 3.23 & 0.0799 & 0.3281 & 0.0728 & 0.8824 & 0.2870 \\
\hline 19 & 66 & $9.98 \mathrm{E}+02$ & $6.67 \mathrm{E}+03$ & 3 & 0.329 & 148 & 3.21 & 0.0779 & 0.3413 & 0.0708 & 0.9023 & 0.3048 \\
\hline 20 & 66 & $9.98 \mathrm{E}+02$ & $6.67 \mathrm{E}+03$ & 3 & 0.330 & 165 & 3.27 & 0.0746 & 0.3914 & 0.0689 & 0.9331 & 0.32780 \\
\hline \multicolumn{13}{|c|}{ Effect of Eötvös number (Eo) } \\
\hline 21 & 6 & $9.98 \mathrm{E}+02$ & $6.67 \mathrm{E}+03$ & 3 & 0.031 & 2.6 & 3.06 & 0.0440 & 0.0540 & 0.1290 & 0 & 0 \\
\hline 22 & 10 & $9.98 \mathrm{E}+02$ & $6.67 \mathrm{E}+03$ & 3 & 0.118 & 9.9 & 3.14 & 0.0765 & 0.1179 & 0.1510 & 0 & 0 \\
\hline 23 & 20 & $9.98 \mathrm{E}+02$ & $6.67 \mathrm{E}+03$ & 3 & 0.216 & 18.2 & 3.1 & 0.1033 & 0.1631 & 0.1360 & 0 & 0 \\
\hline 24 & 40 & $9.98 \mathrm{E}+02$ & $6.67 \mathrm{E}+03$ & 3 & 0.272 & 22.9 & 3.06 & 0.1221 & 0.1797 & 0.1069 & 0 & 0 \\
\hline 25 & 66 & $9.98 \mathrm{E}+02$ & $6.67 \mathrm{E}+03$ & 3 & 0.290 & 24.3 & 3.1 & 0.1243 & 0.1864 & 0.1086 & 0 & 0 \\
\hline 26 & 70 & $9.98 \mathrm{E}+02$ & $6.67 \mathrm{E}+03$ & 3 & 0.290 & 24.4 & 3.1 & 0.1245 & 0.1873 & 0.1087 & 0 & 0 \\
\hline 27 & 80 & $9.98 \mathrm{E}+02$ & $6.67 \mathrm{E}+03$ & 3 & 0.292 & 24.5 & 3.1 & 0.1247 & 0.1884 & 0.1089 & 0 & 0 \\
\hline 28 & 100 & $9.98 \mathrm{E}+02$ & $6.67 \mathrm{E}+03$ & 3 & 0.295 & 24.8 & 3.12 & 0.1251 & 0.1907 & 0.1092 & 0.5511 & 0.00561 \\
\hline 29 & 120 & $9.98 \mathrm{E}+02$ & $6.67 \mathrm{E}+03$ & 3 & 0.296 & 24.9 & 3.12 & 0.1253 & 0.1916 & 0.1093 & 0.1796 & 0.01633 \\
\hline 30 & 140 & $9.98 \mathrm{E}+02$ & $6.67 \mathrm{E}+03$ & 3 & 0.297 & 25.0 & 3.14 & 0.1253 & 0.1921 & 0.1094 & 0.2323 & 0.01947 \\
\hline 31 & 150 & $9.98 \mathrm{E}+02$ & $6.67 \mathrm{E}+03$ & 3 & 0.298 & 25.0 & 3.14 & 0.1254 & 0.1924 & 0.1095 & 0.2227 & 0.02507 \\
\hline 32 & 160 & $9.98 \mathrm{E}+02$ & $6.67 \mathrm{E}+03$ & 3 & 0.298 & 25.1 & 3.14 & 0.1254 & 0.1931 & 0.1097 & 0.2290 & 0.02702 \\
\hline 33 & 170 & $9.98 \mathrm{E}+02$ & $6.67 \mathrm{E}+03$ & 3 & 0.298 & 25.1 & 3.14 & 0.1255 & 0.1930 & 0.1096 & 0.2552 & 0.0246 \\
\hline 34 & 180 & $9.98 \mathrm{E}+02$ & $6.67 \mathrm{E}+03$ & 3 & 0.298 & 25.1 & 3.14 & 0.1251 & 0.1940 & 0.1102 & 0.2556 & 0.0318 \\
\hline 35 & 200 & $9.98 \mathrm{E}+02$ & $6.67 \mathrm{E}+03$ & 3 & 0.299 & 25.1 & 3.16 & 0.1251 & 0.1941 & 0.1101 & 0.2730 & 0.03241 \\
\hline 36 & 250 & $9.98 \mathrm{E}+02$ & $6.67 \mathrm{E}+03$ & 3 & 0.301 & 25.3 & 2.98 & 0.1249 & 0.1951 & 0.1109 & 0.3734 & 0.10823 \\
\hline 37 & 300 & $9.98 \mathrm{E}+02$ & $6.67 \mathrm{E}+03$ & 3 & 0.301 & 25.3 & 3 & 0.1250 & 0.1955 & 0.1110 & 0.4246 & 0.08719 \\
\hline 38 & 350 & $9.98 \mathrm{E}+02$ & $6.67 \mathrm{E}+03$ & 3 & 0.299 & 25.1 & 2.9 & 0.1247 & 0.1944 & 0.1107 & 0.4875 & 0.17962 \\
\hline 39 & 400 & $9.98 \mathrm{E}+02$ & $6.67 \mathrm{E}+03$ & 3 & 0.299 & 25.2 & 2.89 & 0.1248 & 0.1926 & 0.1096 & 0.5867 & 0.13278 \\
\hline 40 & 500 & $9.98 \mathrm{E}+02$ & $6.67 \mathrm{E}+03$ & 3 & 0.301 & 25.3 & 3.04 & 0.1253 & 0.1918 & 0.1094 & 0.5921 & 0.11758 \\
\hline 41 & 600 & $9.98 \mathrm{E}+02$ & $6.67 \mathrm{E}+03$ & 3 & 0.297 & 24.9 & 2.86 & 0.1248 & 0.1953 & 0.1109 & 0.3346 & 0.07387 \\
\hline 42 & 700 & $9.98 \mathrm{E}+02$ & $6.67 \mathrm{E}+03$ & 3 & 0.297 & 24.9 & 2.88 & 0.1247 & 0.1945 & 0.1107 & 0.4989 & 0.09641 \\
\hline
\end{tabular}


Table 2- Mesh dependence test results, $E o=64, R e_{U_{T B}}=60, F r_{U_{T B}}=0.3409$.

\begin{tabular}{cccccccccccc}
\hline Mesh & $\boldsymbol{U}_{T B}$ & $\begin{array}{c}\text { Error } \\
(\boldsymbol{m} / \mathrm{s})\end{array}$ & $\begin{array}{c}\boldsymbol{U}_{T \boldsymbol{L F}} \\
(\%)\end{array}$ & $\begin{array}{c}\text { Error } \\
(\boldsymbol{m})\end{array}$ & $\begin{array}{c}\boldsymbol{\delta}_{L F} \\
(\%)\end{array}$ & $\begin{array}{c}\boldsymbol{\tau}_{W} \\
(\mathbf{P a})\end{array}$ & $\begin{array}{c}\text { Error- } \\
\boldsymbol{\tau}_{W} \\
(\%)\end{array}$ & $\boldsymbol{L}_{\boldsymbol{w}} / \boldsymbol{D}$ & $\begin{array}{c}\text { Error } \\
\boldsymbol{L}_{\boldsymbol{w}} / \boldsymbol{D} \\
(\%)\end{array}$ & $\boldsymbol{V}_{\boldsymbol{w}} / \boldsymbol{D}^{3}$ & $\begin{array}{c}\text { Error } \\
\boldsymbol{V}_{\boldsymbol{w}} / \boldsymbol{D}^{3} \\
(\%)\end{array}$ \\
\hline $26 * 280$ & 0.1431 & 5.03 & 0.001972 & 1.72 & 20.74 & 1.06 & 0.5080 & 8.35 & 0.781 & -5.38 \\
$52 * 560$ & 0.1373 & 1.02 & 0.001947 & 0.46 & 20.58 & 0.29 & 0.480 & 3.04 & 0.805 & -2.24 \\
$104 * 1120$ & 0.1359 & -- & 0.001938 & -- & 20.52 & -- & 0.4654 & -- & 0.823 & -- \\
\hline
\end{tabular}

Table 3- Numerical, experimental, and theoretical values for some of the main hydrodynamic characteristics of experimental case based on work of Nogueira et al. (2006a\&b) with $E o=186, R_{U_{T B}}=37.083, F r_{U_{T B}}=0.3355$, and their respective deviations.

\begin{tabular}{|c|c|c|c|c|c|}
\hline \multicolumn{6}{|c|}{ 1. Taylor bubble rise velocity-Froude number } \\
\hline \multicolumn{3}{|c|}{ Simulation } & \multicolumn{2}{|c|}{ Experimental } & \multirow{2}{*}{$\begin{array}{c}\text { Theoretical } \\
0.3309^{c}\end{array}$} \\
\hline$F r_{U_{T B}}$ & $(-)$ & 0.3094 & $0.3355^{\mathrm{a}}$ & $0.3055^{\mathrm{b}}$ & \\
\hline Error & $(\%)$ & & 7.80 & -1.26 & 6.50 \\
\hline \multicolumn{6}{|c|}{ 2. Flow in the liquid film region } \\
\hline \multicolumn{3}{|c|}{ Simulation } & \multicolumn{2}{|c|}{ Experimental } & Theoretical \\
\hline$\delta_{L F}$ & (m) & 0.0037 & \multicolumn{2}{|c|}{$0.00384^{\mathrm{a}}$} & $0.00382^{\mathrm{d}}$ \\
\hline Error & $(\%)$ & & \multicolumn{2}{|c|}{2.73} & 2.37 \\
\hline$\tau_{W}$ & $(\mathrm{~Pa})$ & 39.83 & \multicolumn{2}{|c|}{$39.6^{\mathrm{a}}$} & $40.75^{\mathrm{d}}$ \\
\hline Error & $(\%)$ & & \multicolumn{2}{|c|}{-0.59} & 2.22 \\
\hline$U_{L F}$ & $(\mathrm{~m} / \mathrm{s})$ & 0.279 & \multicolumn{2}{|c|}{$0.253^{\mathrm{a}}$} & -- \\
\hline Error & $(\%)$ & & \multicolumn{2}{|c|}{-10.02} & -- \\
\hline \multicolumn{6}{|c|}{ 3. Flow in the wake region } \\
\hline \multicolumn{3}{|c|}{ Simulation } & \multicolumn{2}{|c|}{ Experimental } & Theoretical \\
\hline$L_{w} / D$ & $(-)$ & 0.371 & $0.19^{\mathrm{a}}$ & $0.4347^{\mathrm{e}}$ & -- \\
\hline Error & $(\%)$ & & 48.78 & -17.19 & -- \\
\hline$V_{w} / D^{3}$ & $(-)$ & 0.069 & $0.04^{\mathrm{a}}$ & $0.0828^{\mathrm{e}}$ & -- \\
\hline Error & $(\%)$ & & 42.67 & -18.49 & -- \\
\hline & $\begin{array}{l}\mathrm{a} \\
\mathrm{b} \\
\mathrm{c} \\
\mathrm{d} \\
\mathrm{e}\end{array}$ & $\begin{array}{l}\text { Nogueira et } \\
\text { Viana et al. } \\
\text { Wallis (1969 } \\
\text { Brown (196 } \\
\text { Campos and }\end{array}$ & $\begin{array}{l}\text { 2006a\&b) } \\
\text { 3) } \\
\text { Carvalho ( }\end{array}$ & & \\
\hline
\end{tabular}


Table 4- Numerical and experimental values of $L_{W} / D$, and $V_{W} / D^{3}$, and their respective deviations with respect to experimental data

\section{Experimental data ${ }^{a}$}

\begin{tabular}{|c|c|c|c|c|}
\hline & $L_{w} / D(-)$ & Error $(\%)$ & $V_{w} / D^{3}(-)$ & Error $(\%)$ \\
\hline Case 1 & 0.5145 & -- & 0.1319 & -- \\
\hline Case 2 & 0.544 & -- & 0.147 & -- \\
\hline \multicolumn{5}{|c|}{ 2. Current simulation } \\
\hline & $L_{w} / D(-)$ & Error $(\%)$ & $V_{w} / D^{3}(-)$ & Error $(\%)$ \\
\hline Case 1 & 0.487 & 5.34 & 0.1094 & 17.06 \\
\hline Case 2 & 0.5567 & -2.33 & 0.1394 & 5.17 \\
\hline \multicolumn{5}{|c|}{ 3. Experimental correlation ${ }^{a}$} \\
\hline & $L_{w} / D(-)$ & Error $(\%)$ & $V_{w} / D^{3}(-)$ & Error $(\%)$ \\
\hline Case 1 & 0.5145 & -- & 0.0973 & 26.23 \\
\hline Case 2 & 0.5498 & -1.07 & 0.1227 & 16.53 \\
\hline \multicolumn{5}{|c|}{ 4. Numerical correlation ${ }^{b}$} \\
\hline & $L_{w} / D(-)$ & Error $(\%)$ & $V_{w} / D^{3}(-)$ & Error $(\%)$ \\
\hline Case 1 & 0.40616 & 21.06 & 0.0817 & 38.06 \\
\hline Case 2 & 0.4754 & 12.61 & 0.1051 & 28.50 \\
\hline
\end{tabular}




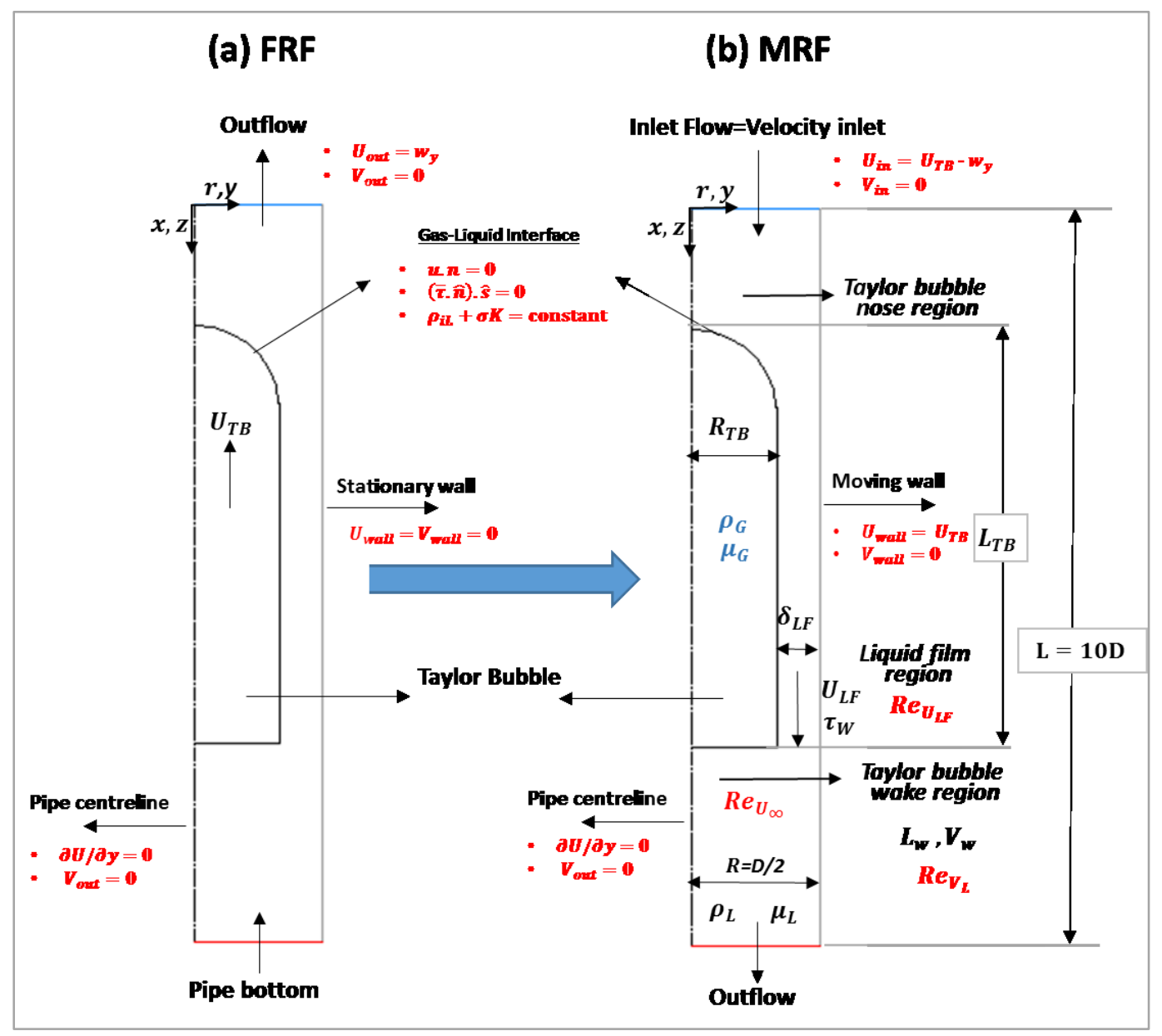

Figure 1. Schematic representation of the computational domain and the main hydrodynamic features of a single Taylor bubble rising through stagnant liquid showing the different flow regions based on the definition of Reynolds number (Mayor et al., 2007), the initial and boundary conditions, the change from a fixed reference frame system (a) to a moving reference frame system (b). 


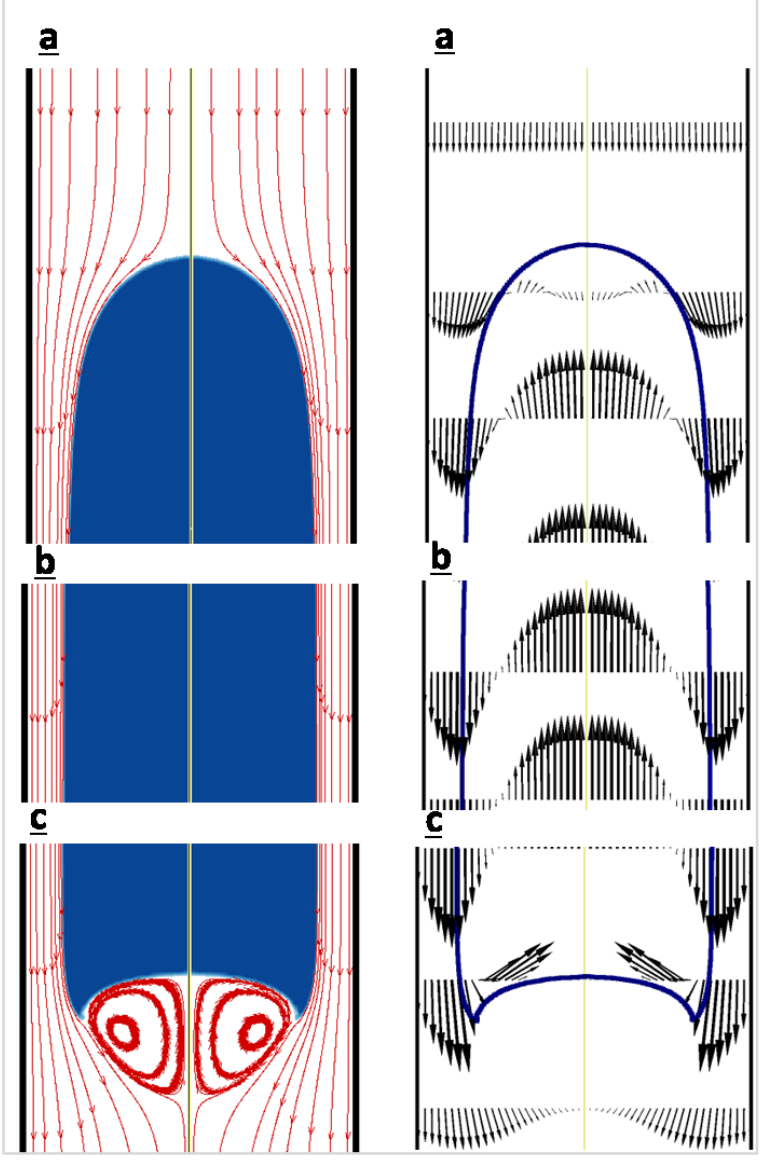

Figure 2. Numerical results of the Streamlines (left) and Velocity fields (right) of a rising Taylor bubble through stagnant liquid vertical pipe, $\boldsymbol{E} \boldsymbol{o}=186, \boldsymbol{R}_{U_{T B}}=37.083, \boldsymbol{F} \boldsymbol{r}_{U_{T B}}=0.3355$ using moving reference frame (MRF).

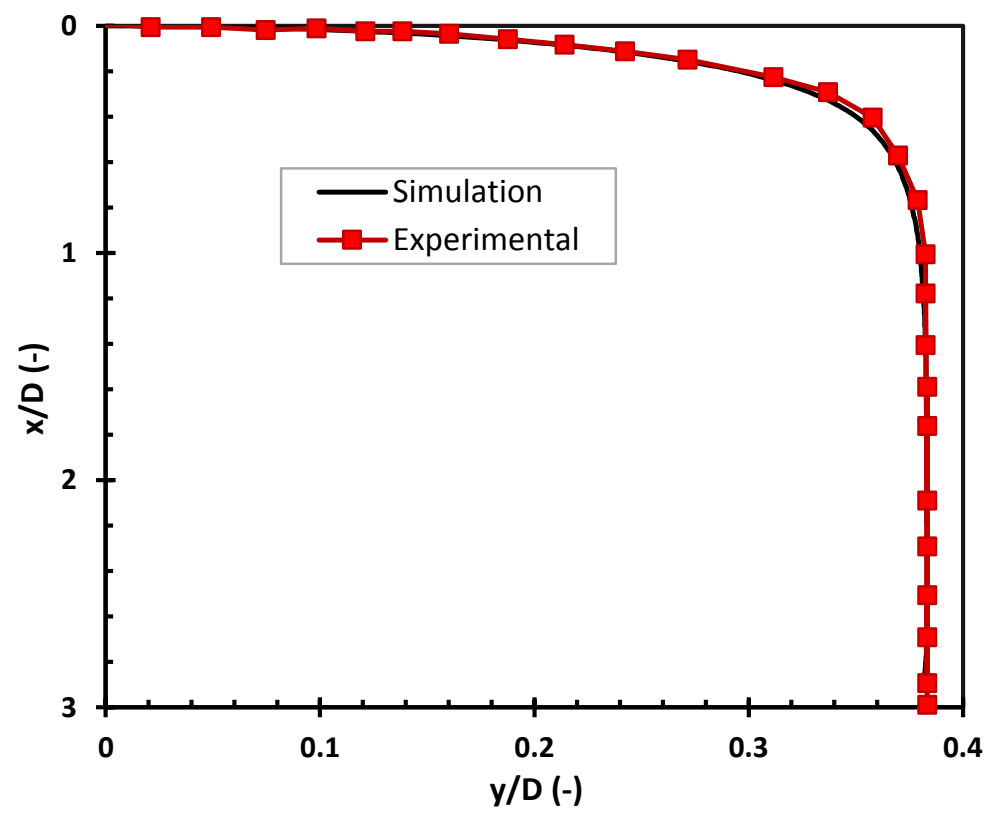

Figure 3. The experimental and numerical shape of Taylor bubble in nose region- $\mathrm{x}$ is the axial distance from bubble nose. 

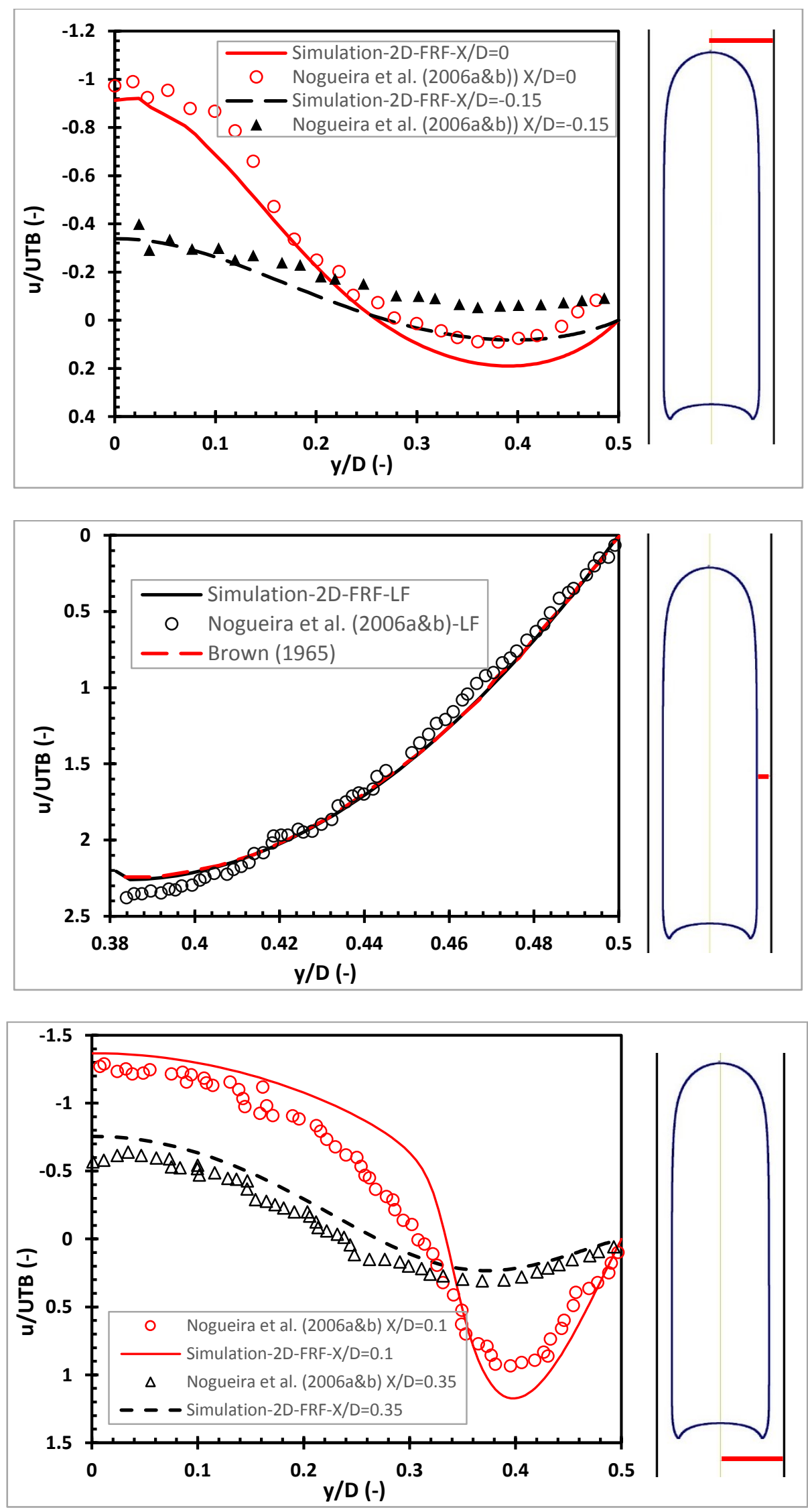

Figure 4. Numerical, experimental, and theoretical dimensionless axial velocity profile for three different regions: Taylor bubble nose region, liquid film region, and wake region in a fixed reference frame. Eo $=186$, $\boldsymbol{R} \boldsymbol{e}_{U_{T B}}=37.083, \boldsymbol{F r}_{U_{T B}}=0.3355$. 


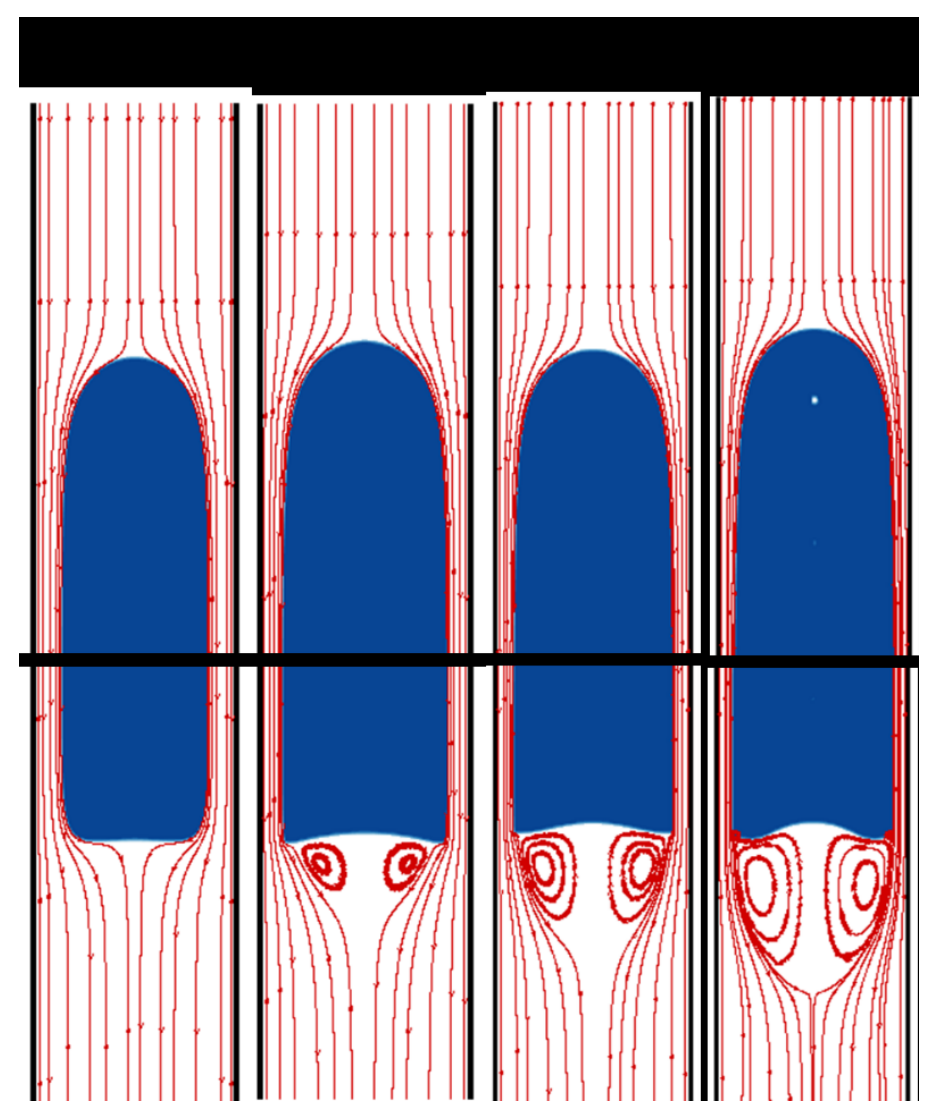

Figure 5. Effect of $R e_{U_{T B}}$ on the terminal shape of Taylor bubble, and streamlines representing the flow field. (a) Case (11) $R e_{U_{T B}}=12$, (b) Case (13) $R e_{U_{T B}}=46$, (c) Case (15) $R e_{U_{T B}}=80$, and (d) Case (18) $R e_{U_{T B}}=131$.

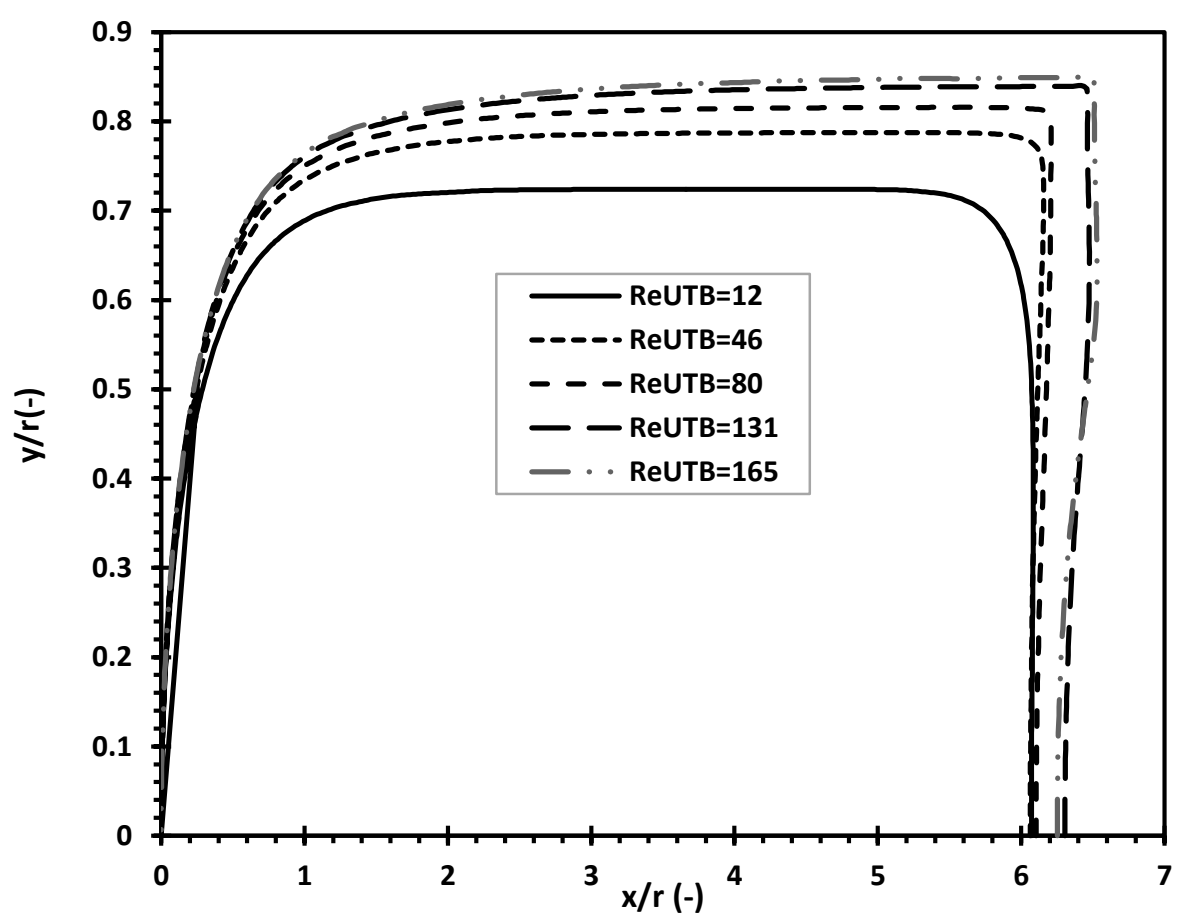

Figure 6. Effect of $R e_{U_{T B}}$ on bubble shape profile- $\mathrm{x}$ is the axial distance from bubble nose. 


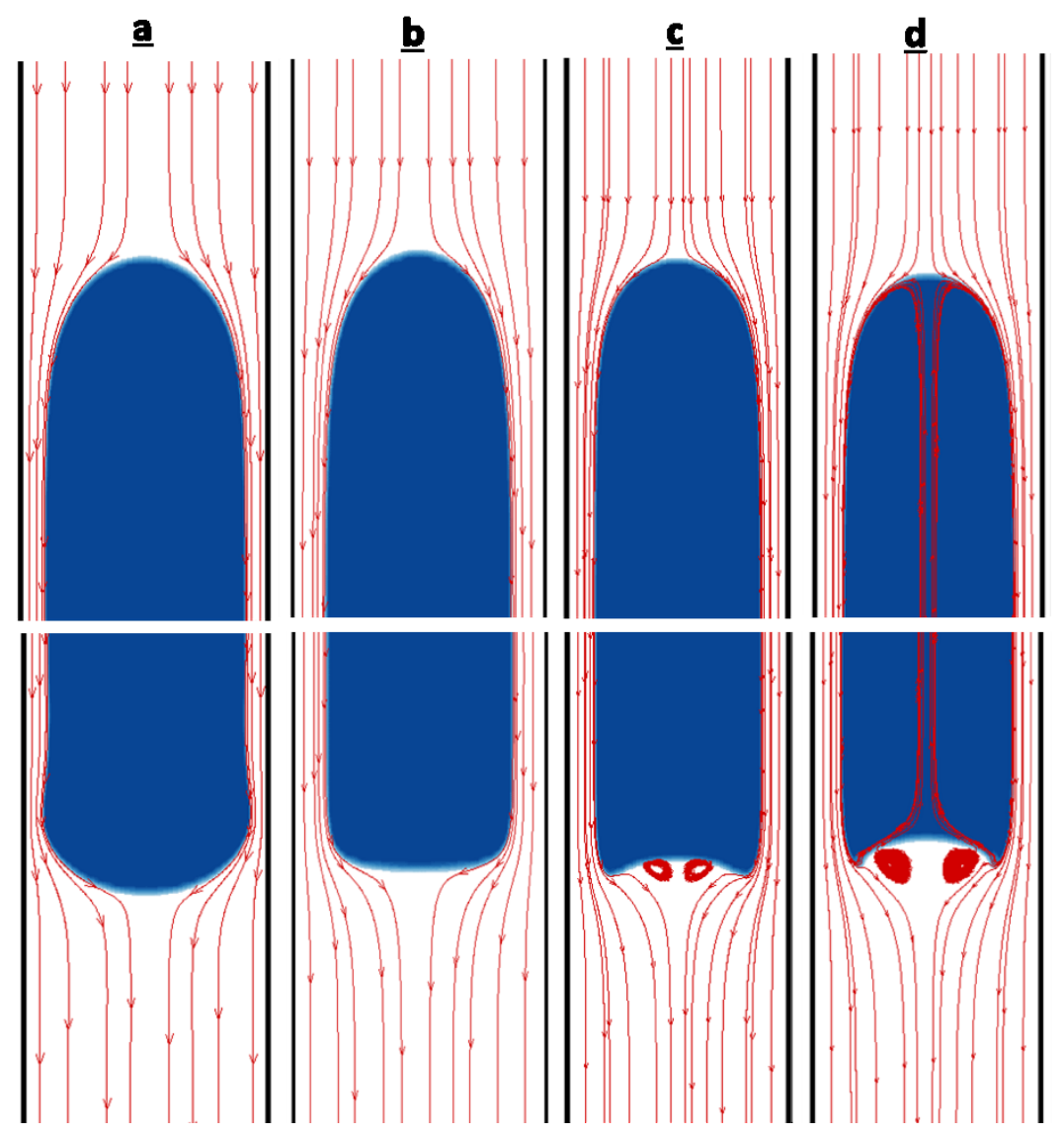

Figure 7. Effect of $E o$ on the terminal shape of Taylor bubble, and streamlines representing the flow field. (a) Case (22) $E o=10$, (b) Case (25) $E o=66$, (c) Case (28) $E o=100$, and (d) Case (32) $E o=160$.

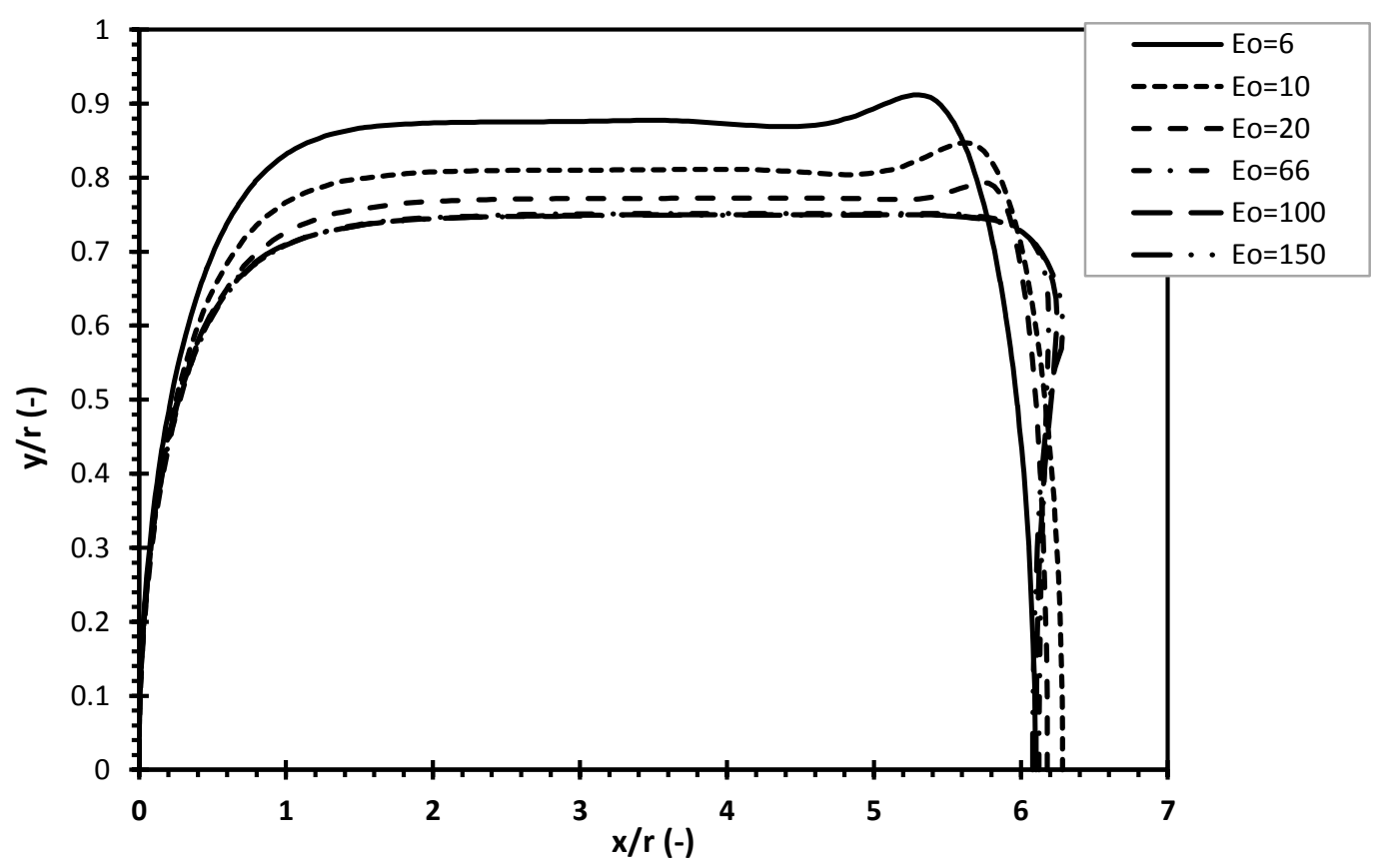

Figure 8. Effect of Eo on bubble shape profile - $\mathrm{x}$ is the axial distance from bubble nose. 


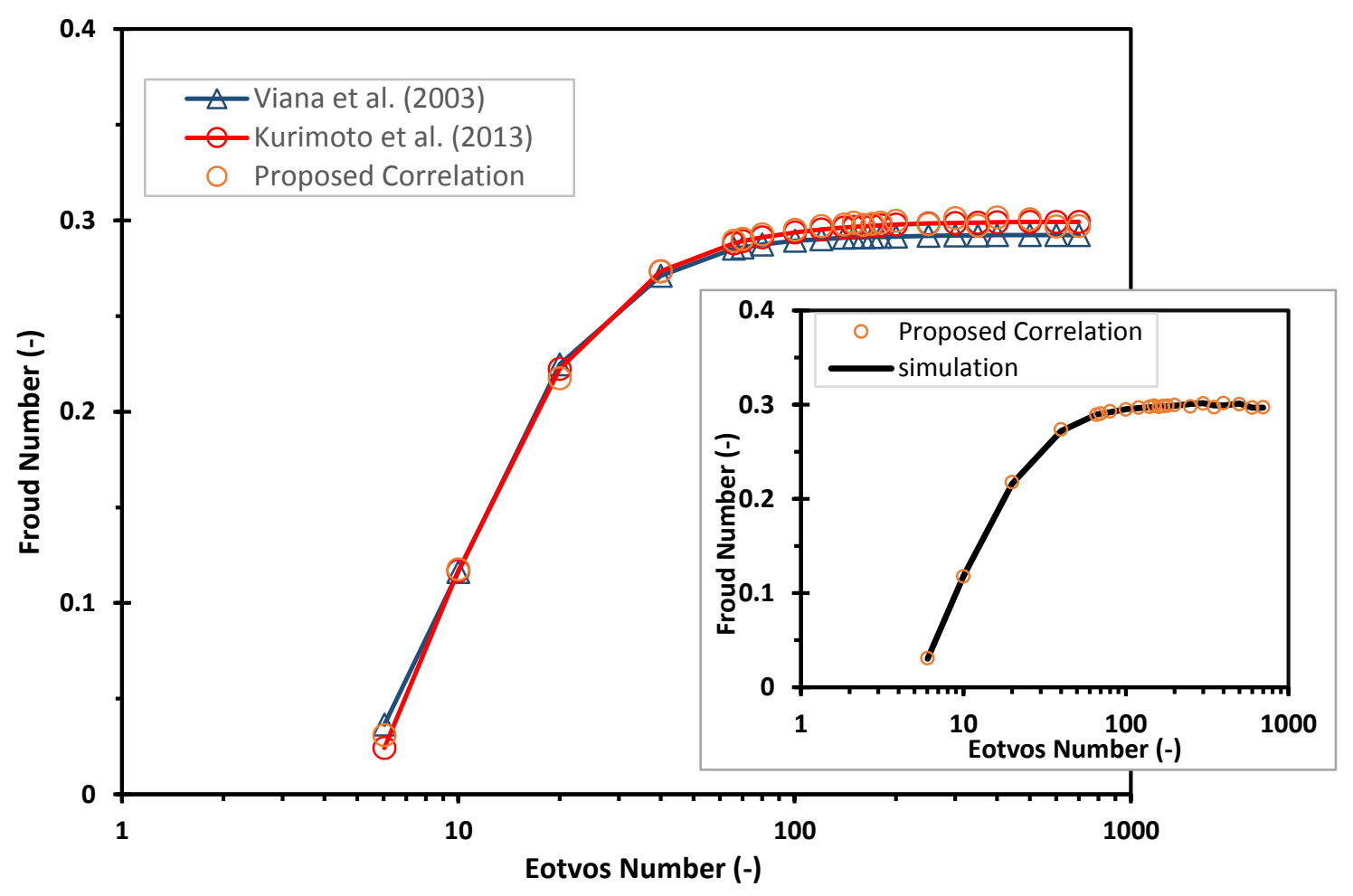

Figure 9. Numerical results of $U_{T B}$ expressed in terms of $F r_{U_{T B}}$ for a several $E o$ with corresponding values obtained from proposed correlation given in equation (17), and different correlations from literature for comparison. $R e_{U_{T B}}$ varies from 2.6 to 25.3 .

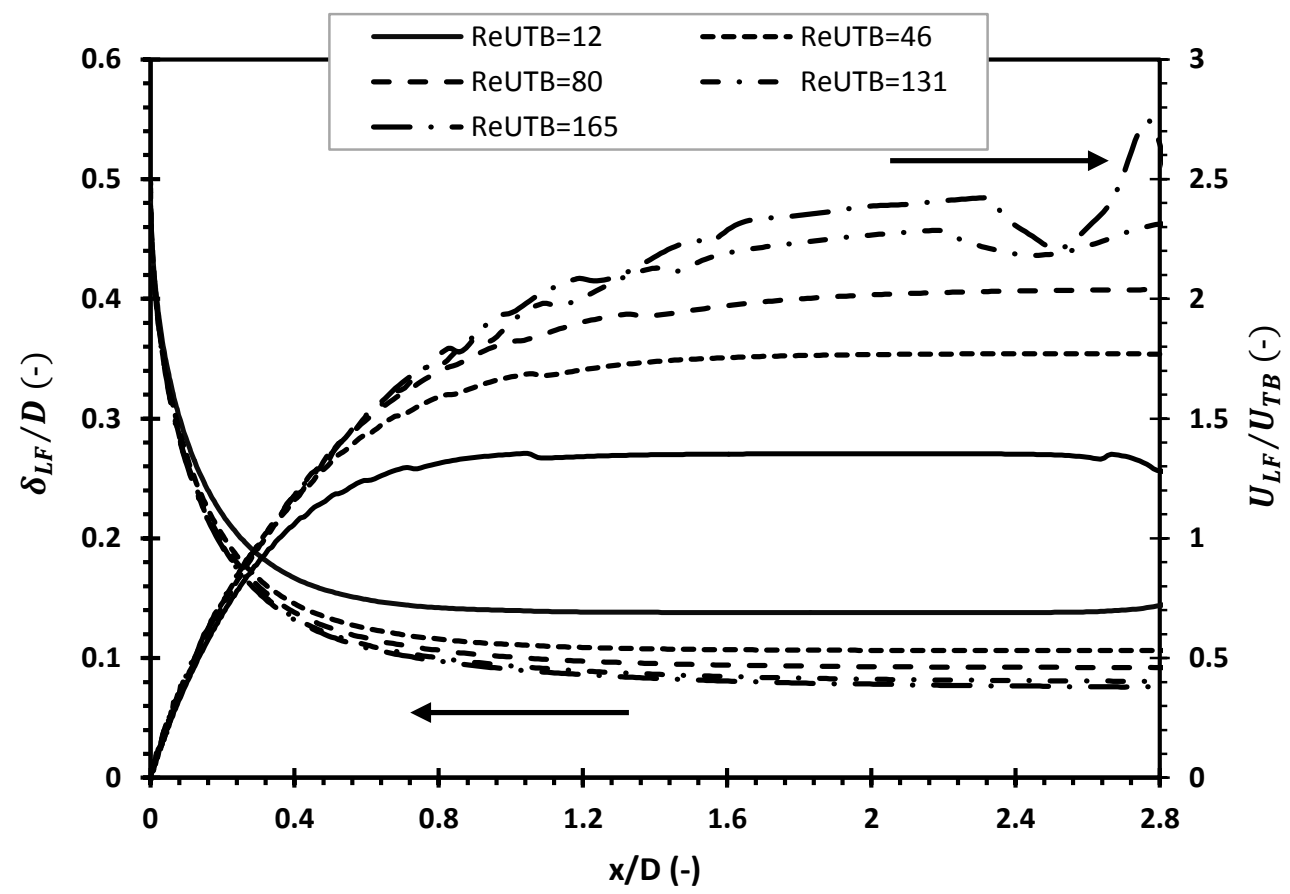

Figure 10. The effect of $R e_{U_{T B}}$ on the dimensionless normalized thicknesses $\left(\delta_{L F} / D\right)$ and dimensionless velocity of falling liquid film $\left(U_{L F} / U_{T B}\right)$ along the Taylor bubble length- $\mathrm{x}$ is axial distance from bubble nose. 


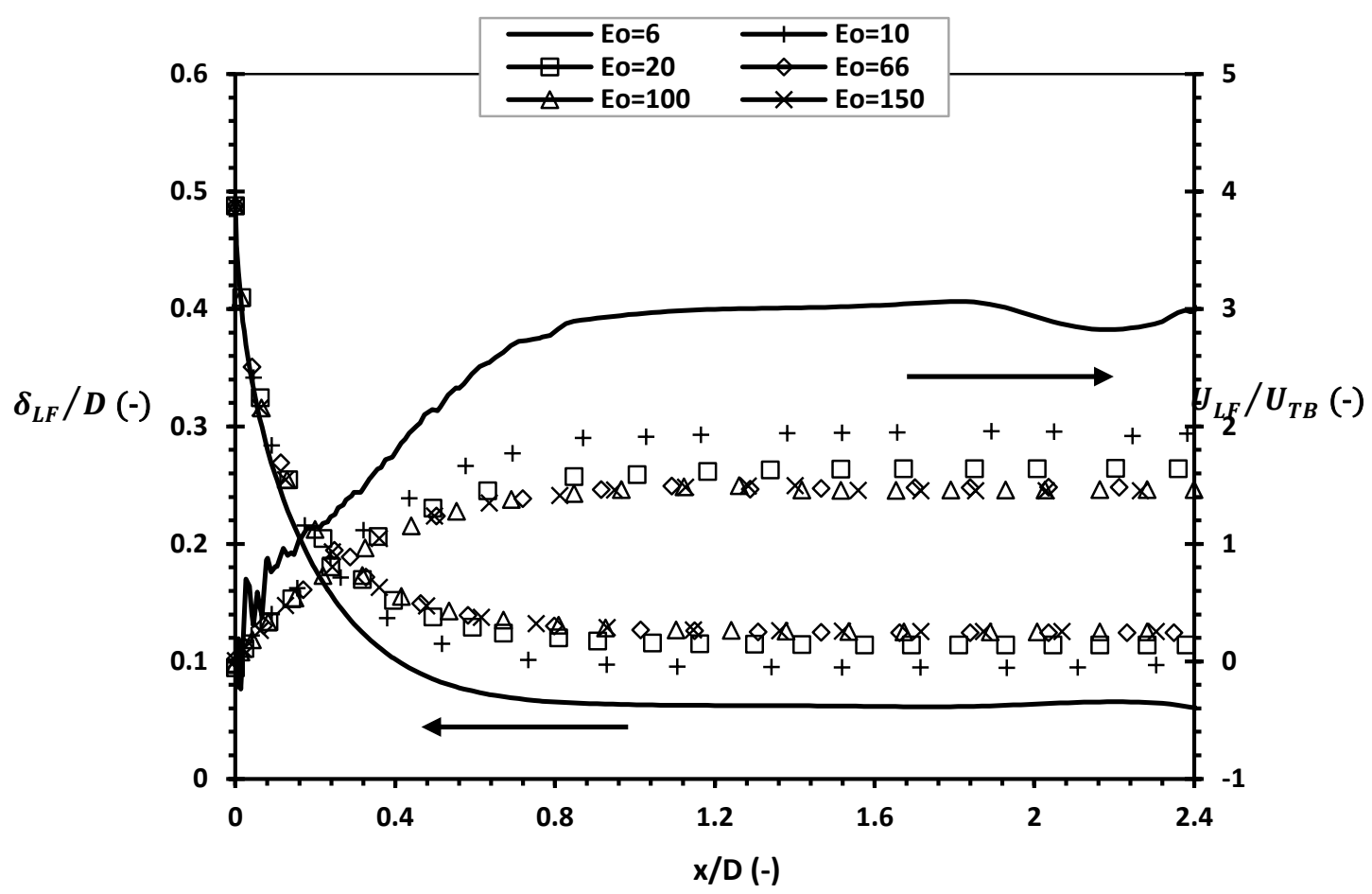

Figure 11. The effect of $E o$ on the dimensionless normalized thicknesses $\left(\delta_{L F} / D\right)$ and dimensionless velocity of falling liquid film $\left(U_{L F} / U_{T B}\right)$ along the Taylor bubble length- $\mathrm{x}$ is axial distance from bubble nose.

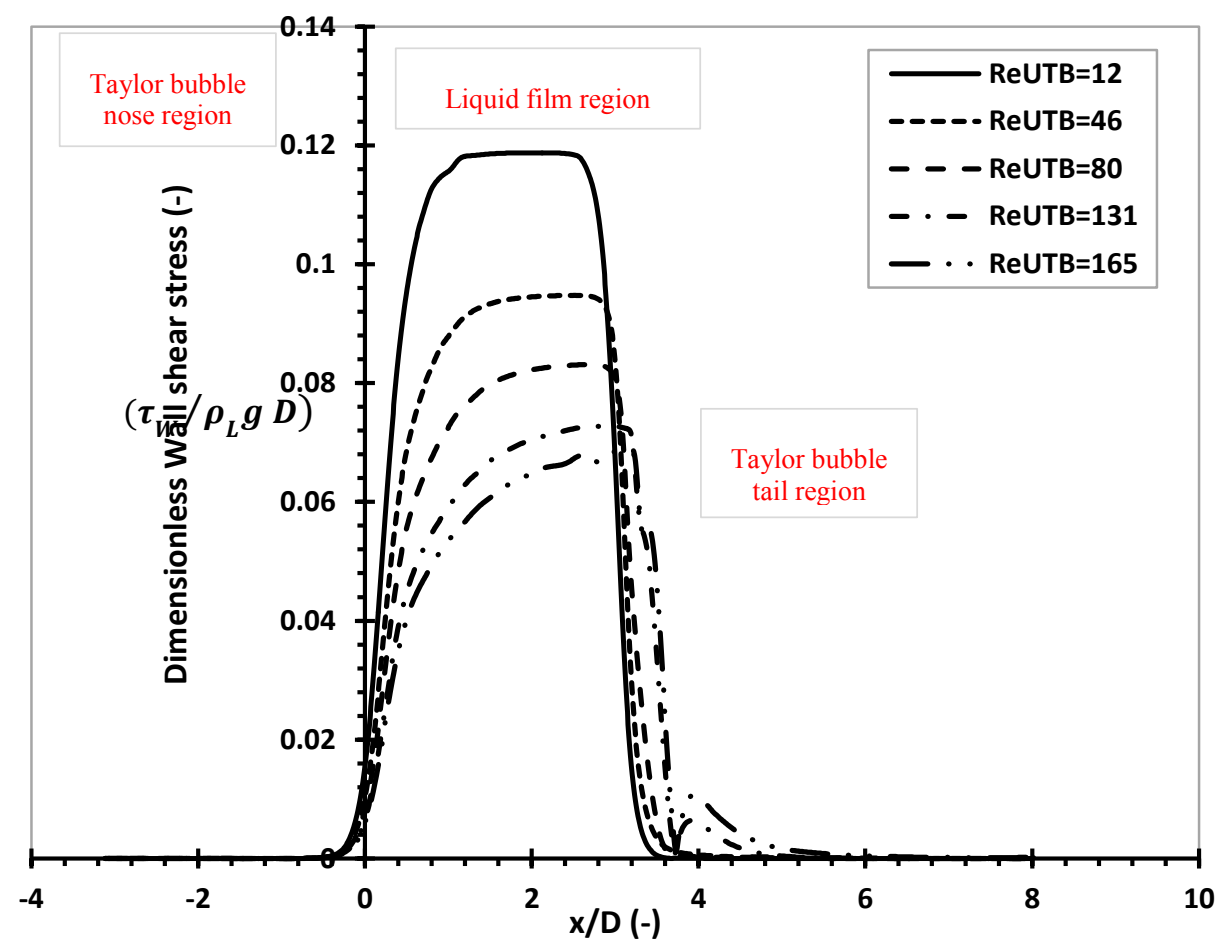

Figure 12. Effect of $R e_{U_{T B}}$ on the wall shear stress distribution $\left(\tau_{W} / \rho_{L} g D\right)$ along Taylor bubble length - $\mathrm{x}$ is axial distance from bubble nose. 


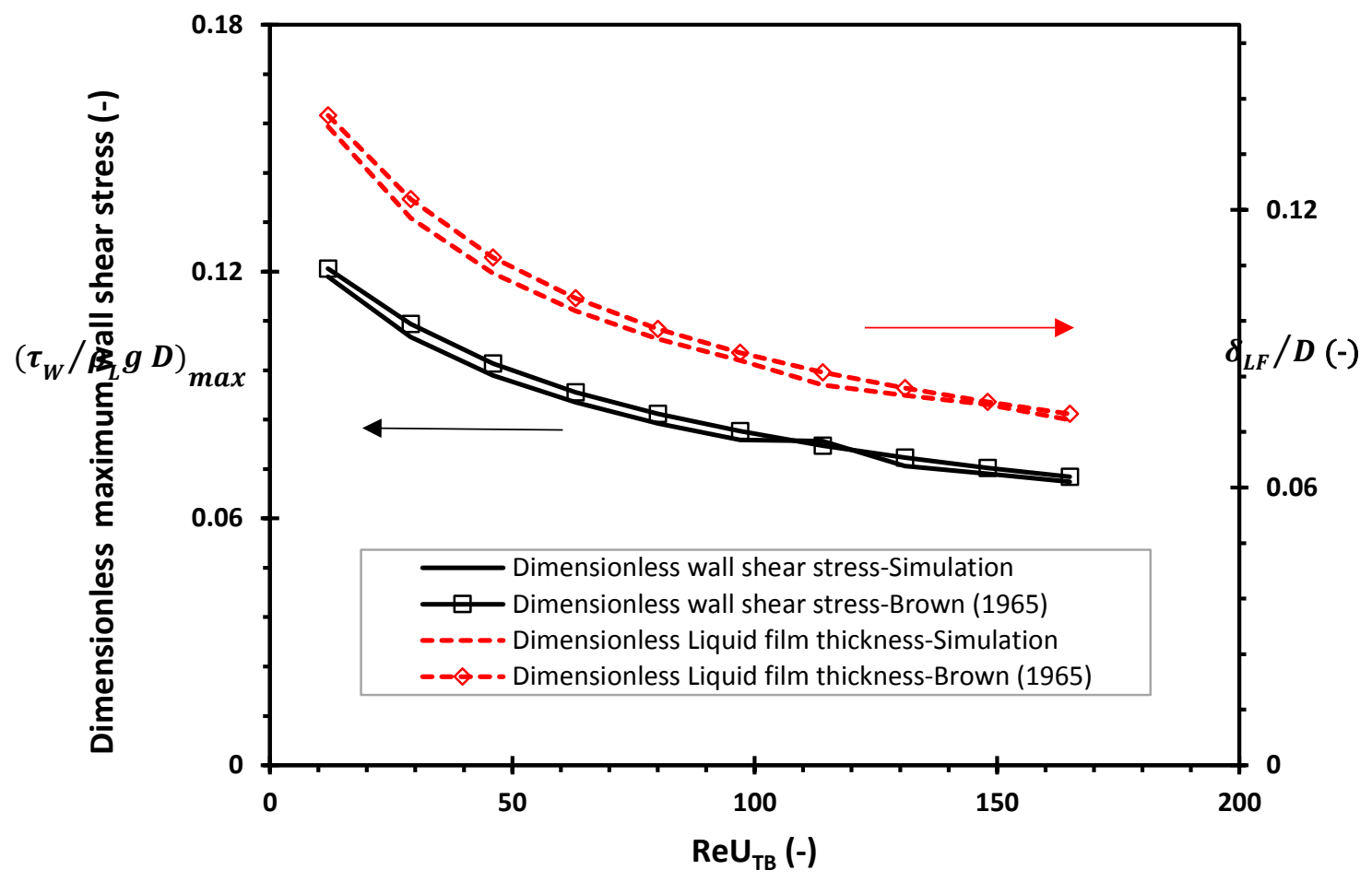

Figure 13. Variation of the dimensionless normalised thickness $\left(\delta_{L F} / D\right)$ and dimensionless maximum wall shear stress $\left(\tau_{W} / \rho_{L} g D\right)_{\max }$ distribution along Taylor bubble length with $R e_{U_{T B}}$ plotted with the theoretical prediction of Brown (1965) (equations (10), and equation (14)).

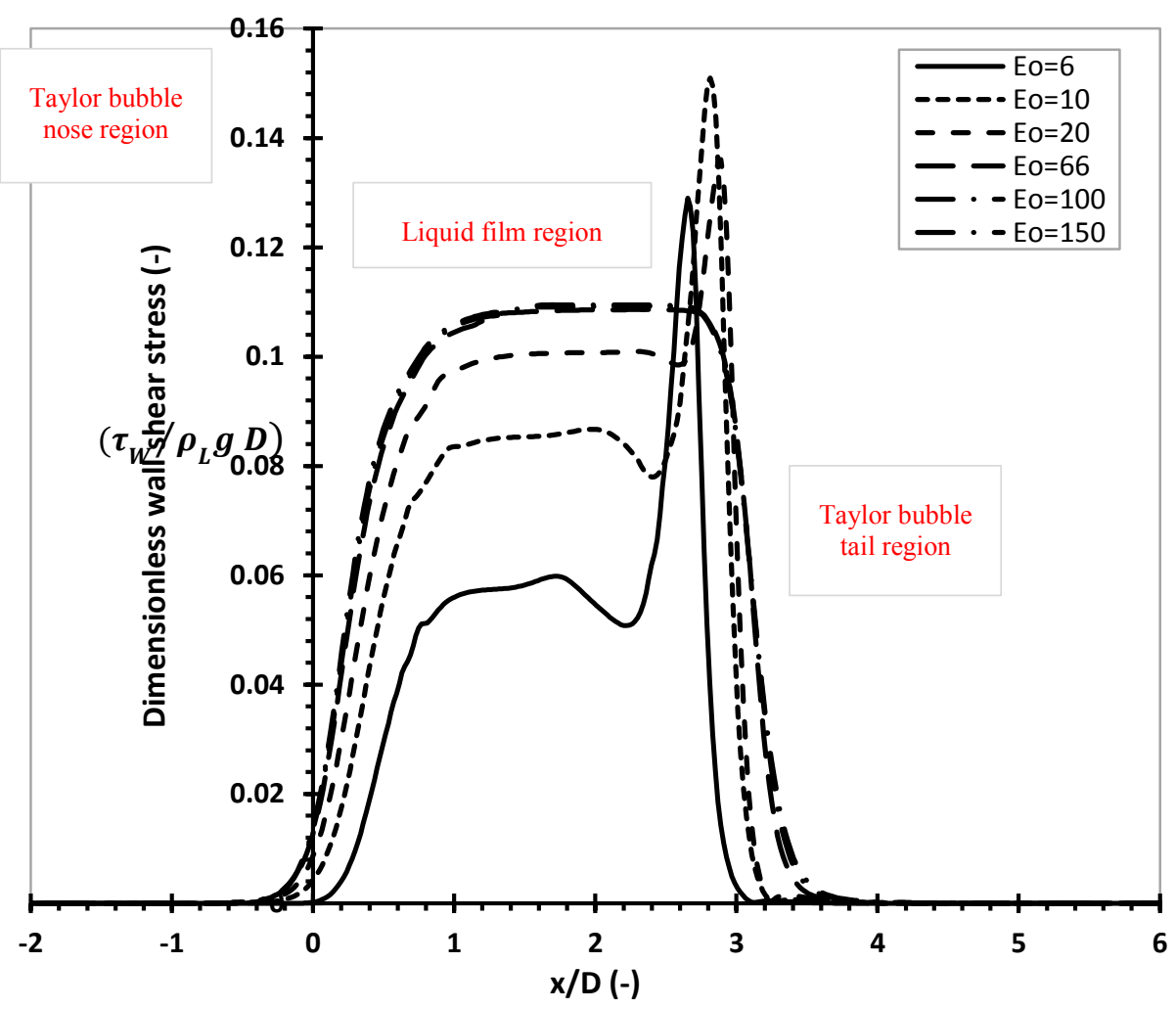

Figure 14. Effect of Eo on the wall shear stress distribution along Taylor bubble length - $\mathrm{x}$ is axial distance from bubble nose, $R e_{U_{T B}}$ varies from 2.6 to 25 . 


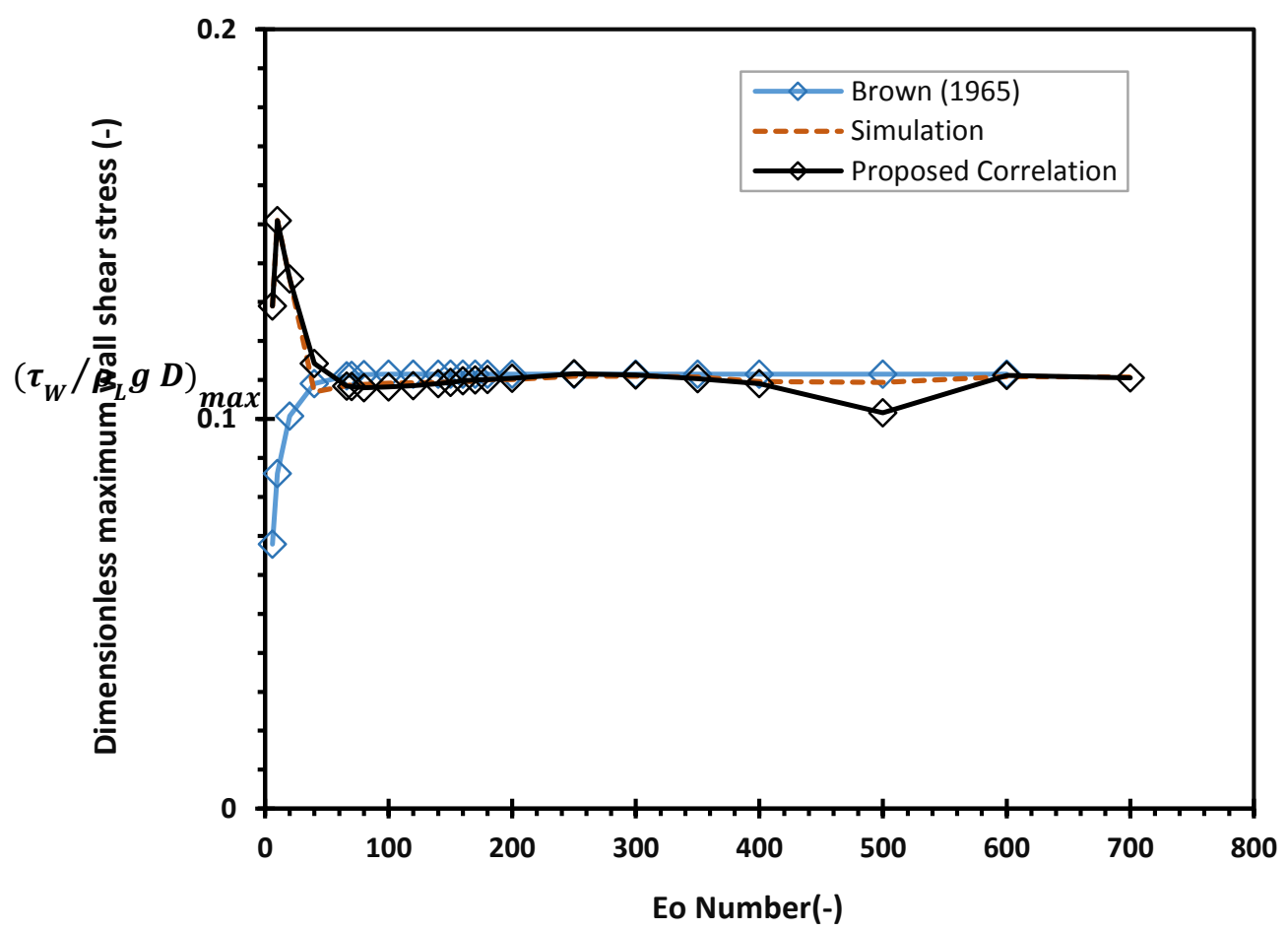

Figure 15. Numerical results of $\left(\frac{\tau_{W}}{\rho_{L} g D}\right)_{\max }$ for a several $E o$ with corresponding values obtained from proposed correlation given in equation (18), theoretical prediction given by Brown (1965) (equation (14)), and predictions using Kang et al. (2010) correlation (equation (19)), for cases 21 to 42 in Table 1.

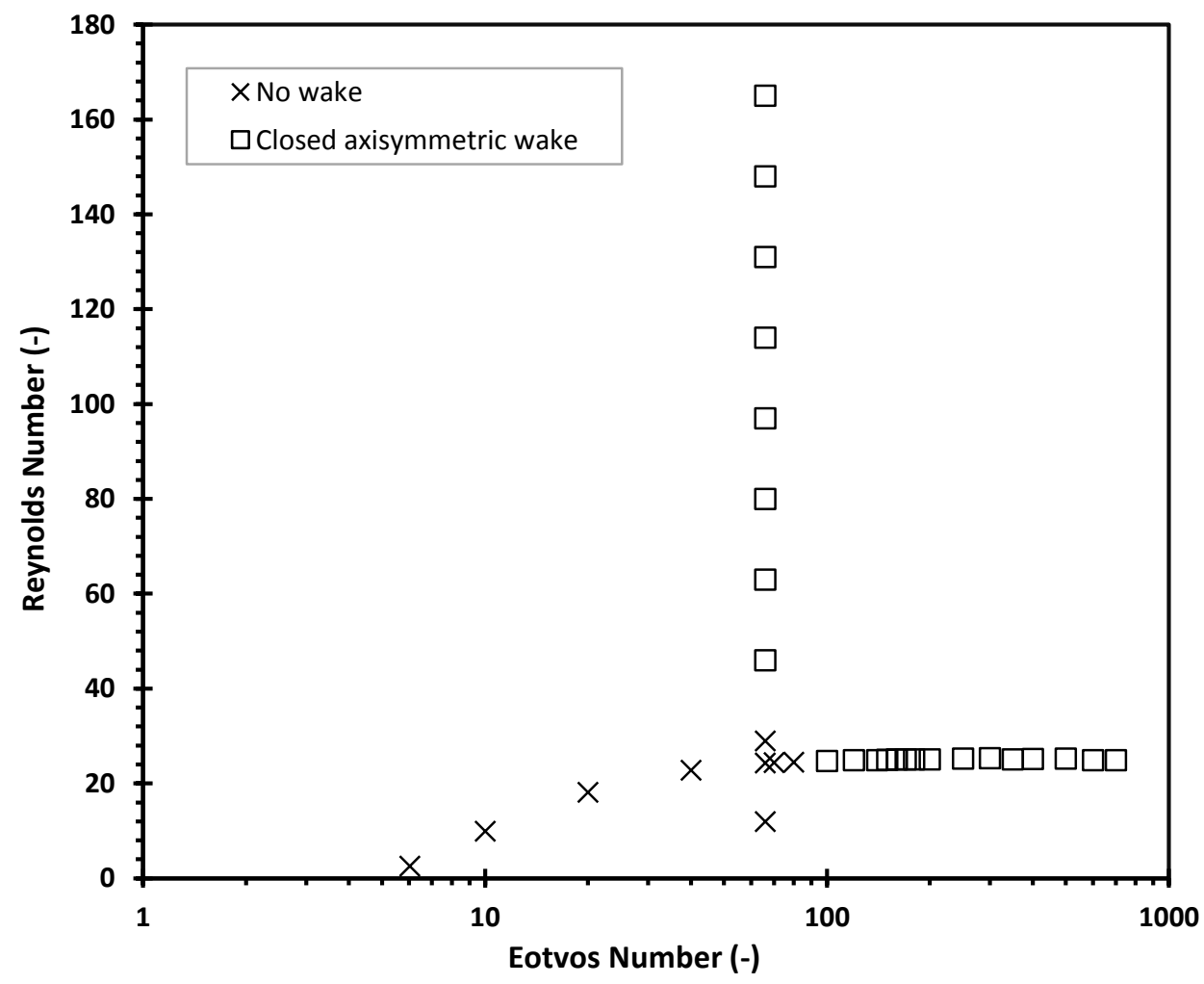

Figure 16. Phase diagram of the presence and kind of wake of Taylor bubbles rising through vertical columns of stagnant liquid. 


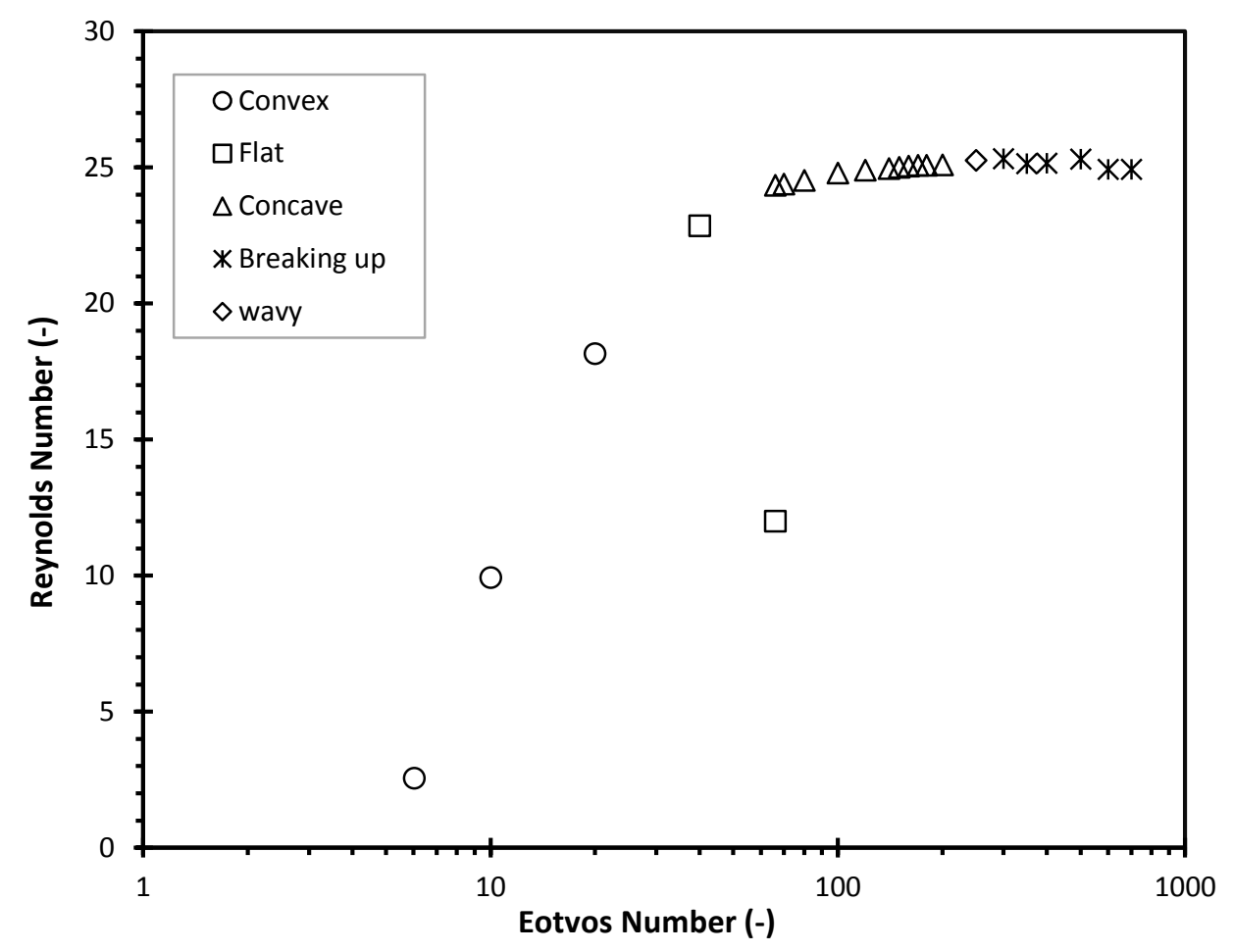

Figure 17. Phase diagram of the rear of Taylor bubble shape, expressed in terms of $\boldsymbol{E} \boldsymbol{o}$, and $\boldsymbol{R e}_{\boldsymbol{U}_{\boldsymbol{T}} \boldsymbol{B}}$, of a Taylor bubbles rising through vertical columns of stagnant liquid.

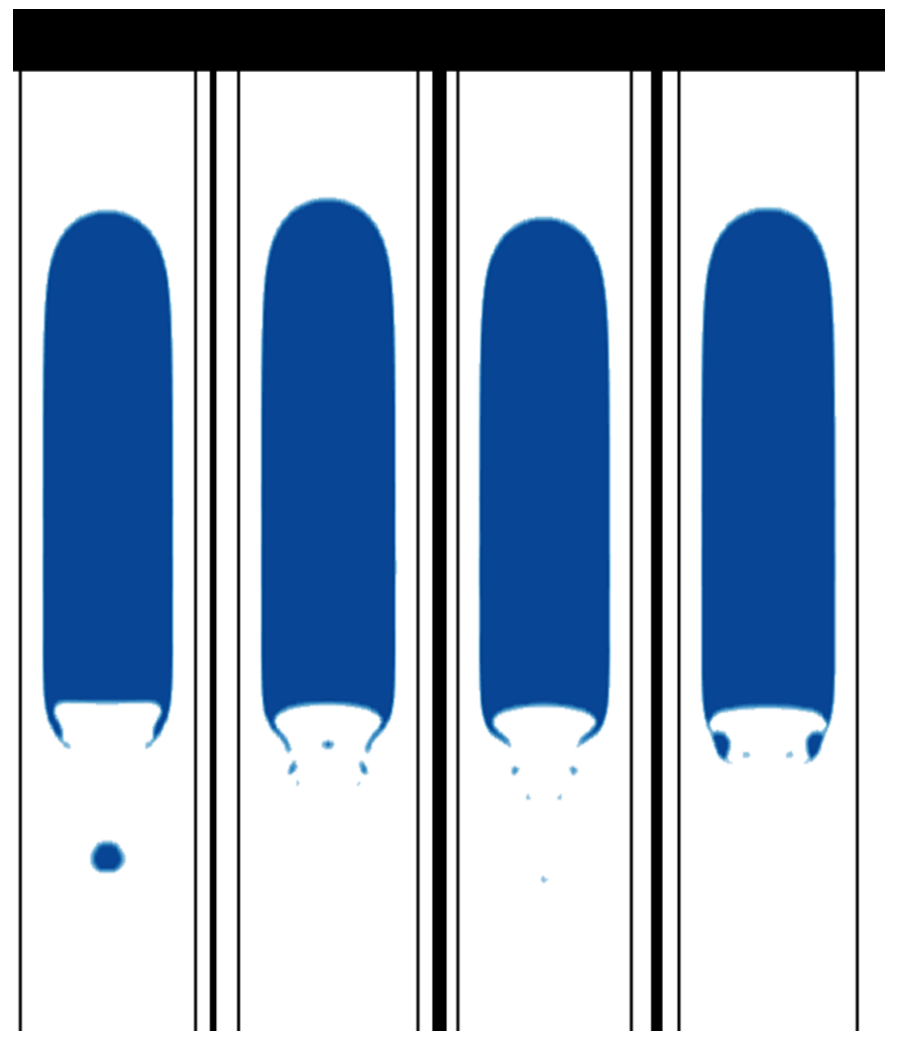

Figure 18. Development of wake flow pattern of Taylor bubble rising vertical columns of stagnant liquid for case (36) with a time interval of $0.5 \mathrm{~s}: E o=250, R e_{U_{T B}}=25.26$, and $F r_{U_{T B}}=0.3$. 


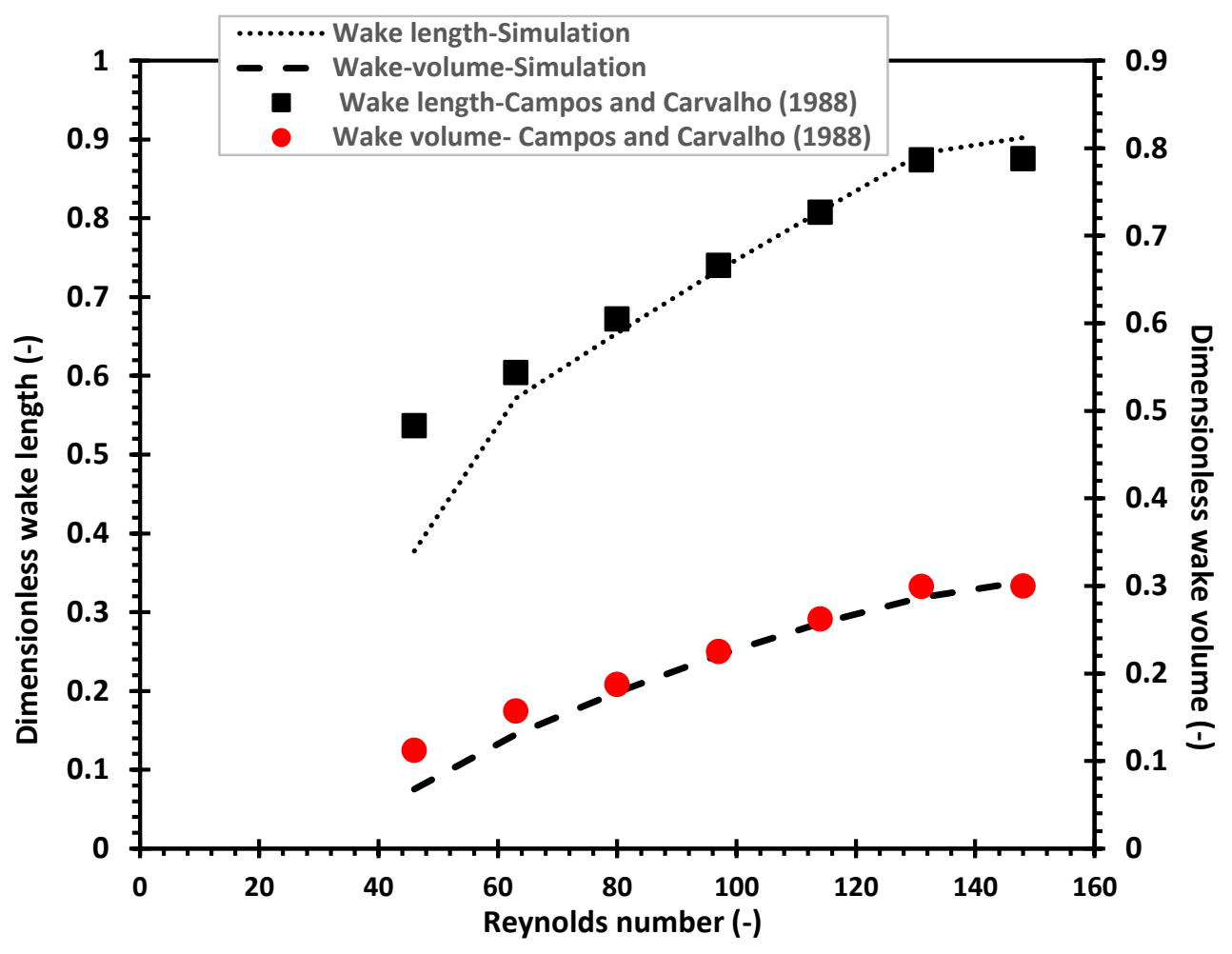

Figure 19. Numerical results of dimensionless wake length $\left(L_{W} / D\right)$, and dimensionless wake volume $\left(V_{W} / D^{3}\right)$ for cases 13 to 19 in Table 1.

\section{Appendix 1- Order of magnitude analysis for the equation of motion}

The Navier-stokes equations in poolar coordinates assuming axismmetric flow are:

$\rho_{L}\left(\frac{\partial v_{r}}{\partial t}+v_{r} \frac{\partial v_{r}}{\partial r}+v_{z} \frac{\partial v_{r}}{\partial z}\right)=\rho_{L} g_{r}-\frac{\partial p}{\partial r}+\mu\left[\frac{\partial^{2} v_{r}}{\partial r^{2}}+\frac{1}{r} \frac{\partial v_{r}}{\partial r}+\frac{\partial^{2} v_{r}}{\partial z^{2}}-\frac{v_{r}}{r^{2}}\right]$

$\rho_{L}\left(\frac{\partial v_{z}}{\partial t}+v_{r} \frac{\partial v_{z}}{\partial r}+v_{z} \frac{\partial v_{z}}{\partial z}\right)=\rho_{L} g_{z}-\frac{\partial p}{\partial z}+\mu\left[4 \frac{\partial^{2} v_{z}}{\partial r^{2}}+\frac{1}{r} \frac{\partial v_{z}}{\partial r}+\frac{\partial^{2} v_{z}}{\partial z^{2}}\right]$

$0=-\frac{1}{r} \frac{\partial p}{\partial \theta} \quad\left(v_{\theta}=0\right)$

And the continuity equation is:

$\frac{\partial v_{r}}{\partial r}+\frac{v_{r}}{r}+\frac{\partial v_{z}}{\partial z}=0$

Introducing the following dimensionless variables:

$$
\begin{aligned}
& v_{r}{ }^{*}=\frac{v_{r}}{U_{T B}}, v_{z}{ }^{*}=\frac{v_{z}}{U_{T B}}, t^{*}=t\left(\frac{U_{T B}}{L_{T B}}\right), r^{*}=\frac{r}{(D / 2)}, z^{*}=\frac{z}{L_{T B}}, p^{*}=\frac{p}{\frac{1}{2} \rho_{L} U_{T B}{ }^{2}}, \\
& g_{r}{ }^{*}=\frac{g_{r}}{g}, g_{z}^{*}=\frac{g_{z}}{g}, \sigma_{r}{ }^{*}=\frac{\sigma_{r}}{\sigma}, \sigma_{z}^{*}=\frac{\sigma_{z}}{\sigma}, \sigma_{\theta}^{*}=\frac{\sigma_{\theta}}{\sigma}, k^{*}=\frac{k}{\left(1 / D^{2}\right)}
\end{aligned}
$$


The Navier-stokes equations and continuity equations in dimensionless form can be summerized as follows:

$$
\begin{aligned}
& \left(\frac{D}{L_{T B}}\right) \frac{\partial v_{r}^{*}}{\partial t^{*}}+2 v_{r}{ }^{*} \frac{\partial v_{r}{ }^{*}}{\partial r^{*}}+\left(\frac{D}{L_{T B}}\right) v_{z}{ }^{*} \frac{\partial v_{r}{ }^{*}}{\partial z^{*}} \\
& =\frac{1}{F r_{U_{T B}}^{2}} g_{r}^{*}-\frac{\partial p^{*}}{\partial r^{*}} \\
& +\frac{1}{R e_{U_{T B}}}\left[4 \frac{\partial^{2} v_{r}^{*}}{\partial r^{* 2}}+\frac{4}{r^{*}} \frac{\partial v_{r}^{*}}{\partial r^{*}}+\left(\frac{D}{L_{T B}}\right)^{2} \frac{\partial^{2} v_{r}^{*}}{\partial z^{* 2}}-\frac{4 v_{r}^{*}}{r^{* 2}}\right] \\
& \left(\frac{D}{L_{T B}}\right) \frac{\partial v_{z}^{*}}{\partial t^{*}}+2 v_{r}^{*} \frac{\partial v_{z}^{*}}{\partial r^{*}}+\left(\frac{D}{L_{T B}}\right) v_{z}^{*} \frac{\partial v_{z}^{*}}{\partial z^{*}} \\
& =\frac{1}{F r_{U_{T B}}^{2}} g_{z}^{*}-\left(\frac{D}{L_{T B}}\right) \frac{\partial p^{*}}{\partial z^{*}}+\frac{1}{R e_{U_{T B}}}\left[4 \frac{\partial^{2} v_{z}^{*}}{\partial r^{* 2}}+\frac{4}{r^{*}} \frac{\partial v_{z}^{*}}{\partial r^{*}}+\left(\frac{D}{L_{T B}}\right)^{2} \frac{\partial^{2} v_{z}^{*}}{\partial z^{* 2}}\right] \\
& 0=\frac{\partial p^{*}}{\partial \theta^{*}} \\
& 2\left(\frac{\partial v_{r}^{*}}{\partial r^{*}}+\frac{v_{r}^{*}}{r^{*}}\right)+\left(\frac{D}{L_{T B}}\right) \frac{\partial v_{z}{ }^{*}}{\partial z^{*}}=0
\end{aligned}
$$

where $\operatorname{Fr}_{\mathrm{U}_{\mathrm{TB}}}=\frac{\mathrm{U}_{\mathrm{TB}}}{\sqrt{\mathrm{gD}}}, \operatorname{Re}_{\mathrm{U}_{\mathrm{TB}}}=\frac{\rho_{\mathrm{L}} \mathrm{U}_{\mathrm{TB}} \mathrm{D}}{\mu_{\mathrm{L}}}$

On the gas-liquid interface, the following conditions are applied:

$$
\begin{aligned}
& {\left[-\frac{\partial p^{*}}{\partial r^{*}}+\frac{1}{F r_{U_{T B}}^{2} E o} k^{*} \sigma_{r}^{*}\right]_{S}+\frac{4}{R e_{U_{T B}}}\left[\frac{\partial^{2} v_{r}^{*}}{\partial r^{* 2}}+\frac{1}{r^{*}} \frac{\partial v_{r}^{*}}{\partial r^{*}}\right]_{S}=0} \\
& {\left[\left(\frac{D}{L_{T B}}\right) \frac{\partial v_{z}^{*}}{\partial t^{*}}+\left(\frac{D}{L_{T B}}\right) \frac{\partial v_{z}^{*}}{\partial r^{*}}+\left(\frac{D}{L_{T B}}\right) v_{z}^{*} \frac{\partial v_{z}^{*}}{\partial z^{*}}\right]_{S}} \\
& =\left[-\left(\frac{D}{L_{T B}}\right) \frac{\partial p^{*}}{\partial z^{*}}\right]_{S}+\frac{1}{R e_{U_{T B}}}\left[4 \frac{\partial^{2} v_{z}^{*}}{\partial r^{* 2}}+\frac{4}{r^{*}} \frac{\partial v_{z}^{*}}{\partial r^{*}}+\left(\frac{D}{L_{T B}}\right)^{2} \frac{\partial^{2} v_{z}^{*}}{\partial z^{* 2}}\right]_{S} \\
& \quad+\frac{1}{F r_{U_{T B}}^{2}}\left[g_{z}^{*}+\frac{1}{E o} k^{*} \sigma_{z}^{*}\right]_{S} \\
& 0=\left[-\frac{1}{r^{*}} \frac{\partial p^{*}}{\partial \theta^{*}}\right]_{S}+\frac{1}{F r_{U_{T B}}^{2} E o}\left[k^{*} \sigma_{\theta}^{*}\right]_{S}
\end{aligned}
$$

where $\mathrm{Eo}=\frac{\mathrm{g} \rho_{\mathrm{L}} \mathrm{D}^{2}}{\sigma}$

Performing similar analysis with respect to gas and liquid sides would show the additional dimensionless groups: density ratio $\left(\Gamma_{\rho}\right)$, viscosity ratio $\left(\Gamma_{\mu}\right)$. 
In order to perform order of magnitude analysis to the continuity equation, the following orders are introduced to equation (1-9):

$$
\begin{aligned}
& r^{*}=o(1), z^{*}=o(1), v_{z}{ }^{*}=o(1), k^{*}=o(1), \sigma_{z}^{*}=o(1), g_{z}{ }^{*}=o\left(\frac{D}{L_{T B}}\right) \\
& g_{r}{ }^{*}=o\left(\frac{D}{L_{T B}}\right)^{2} \text { and } t^{*}=o(1)
\end{aligned}
$$

It can be concluded from equations (1-9) and (1-13), inorder to keep the continuity equation intact $v_{r}{ }^{*}$ should be of order $\frac{D}{L_{T B}}$, that is $v_{r}{ }^{*}=o\left(\frac{D}{L_{T B}}\right)$.

Applying the same analysis to momentum equation in the $z^{*}$ direction (equation (1-7)), will give the following:

$$
F r_{U_{T B}}=o(1), R e_{U_{T B}}=o\left(\frac{L_{T B}}{D}\right)
$$

Applying the same analysis to the momentum equation in $r^{*}$ direction (equation (1-6)) and using the conclusion given in equation (1-14), will give the following:

$\frac{\partial p^{*}}{\partial r^{*}}=o\left(\frac{D}{L_{T B}}\right)^{2}, p^{*}=\left(\frac{D}{L_{T B}}\right)^{2}, \therefore \frac{\partial p^{*}}{\partial z^{*}}=o\left(\frac{D}{L_{T B}}\right)^{2}-$ which is very small

Finally, applying the same analysis to the gas-liquid interface (equation (1-11)), gives the following:

$E o=o\left(\frac{L_{T B}}{D}\right)$

It is worth noting that, if the characteristic velocity $U_{T B}$ is placed by a new characteristic velocity $V_{s}=(g D)^{1 / 2}$, the dimensionless variables given in equation (1-5) will be modified as follows;

$\widehat{v_{r}}=\frac{v_{r}}{V_{S}}, \widehat{v_{z}}=\frac{v_{z}}{V_{S}}, \hat{t}=t\left(\frac{V_{S}}{L_{T B}}\right), \hat{p}=\frac{p}{\frac{1}{2} \rho_{L} V_{s}^{2}}$,

Thus for instance, the dimensionless momentum equation in the radial direction (equation (16)) will be as follows: 


$$
\begin{aligned}
\left(\frac{D}{L_{T B}}\right) \frac{\partial \widehat{v_{r}}}{\partial \hat{t}}+2 & \widehat{v_{r}} \frac{\partial \widehat{v_{r}}}{\partial r^{*}}+\left(\frac{D}{L_{T B}}\right) \widehat{v_{z}} \frac{\partial \widehat{v_{r}}}{\partial z^{*}} \\
& =g_{r}{ }^{*}-\frac{\partial \hat{p}}{\partial r^{*}}+\frac{1}{R e_{\text {modified }}}\left[4 \frac{\partial^{2} \widehat{v_{r}}}{\partial r^{* 2}}+\frac{4}{r^{*}} \frac{\partial \widehat{v_{r}}}{\partial r^{*}}+\left(\frac{D}{L_{T B}}\right)^{2} \frac{\partial^{2} \widehat{v_{r}}}{\partial z^{* 2}}-\frac{4 \widehat{v_{r}}}{r^{* 2}}\right]
\end{aligned}
$$

where $R e_{\text {modified }}$ is the modified Reynolds number which is defined as follows:

$$
R e_{\text {modified }}=\frac{V_{s} D}{v}=\frac{(g D)^{1 / 2} D}{v}=\frac{\left(g D^{3}\right)^{1 / 2}}{v}=N_{f}
$$

It can be concluded from equation (1-18) that Froude number disappeared from the dimensionless governing equation as being of order unity as shown in equation (1-14). Hence, in this frame with the new definition of the characteristic velocity $\left(V_{S}\right)$, the inverse viscosity number $\left(N_{f}\right)$ can represent the ratio of inertia force to viscous force and Froude number is no longer a dimensionless parameter. 